\title{
ROLE OF CARNOSINE IN PREVENTION AND TREATMENT OF OSTEOPOROTIC LUMBAR VERTEBRAE OF OVARIECTOMIZED HAMSTERS
}

\author{
Kawther M. Soliman, Hoda M. El-Aasar*, Naglaa A. Ibrahim* \\ and Amal M. Abbas** \\ Departments of Biochemistry, Anatomy* and Histology**, \\ Faculty of Medicine, Cairo University
}

\section{INTRODUCTION}

Estrogen plays an important role in the growth and maturation of bone as well as in the regulation of its turnover to maintain bone balance in adults. During bone growth, estrogen is needed for proper closure of epiphyseal plates both in females and males (Vaananen and Harkonen, 1996). In the adult, both bone formation and resorption occur side by side in a process called remodeling where bone formation equals the amount of that lost during resorption. With aging, resorption becomes more active than formation with a net loss of bone mass (Lindsay et al., 1980). Estrogen withdrawal as a result of menopause or induced by ovariectomy leads to osteoporosis as a result of a decrease in bone formation and an increase in bone resorption (Sun et al., 1997; Chen et al., 2000), however, the decrease in bone formation may precede the increase in bone resorption (SeifertKlauss et al., 2002). The mechanisms which have been suggested for the development of osteoporosis following estrogen withdrawal include stimulation of the production of bone resorbing cytokines which stimulates osteoclast formation in bone marrow (Vaananen and Harkonen, 1996), reduction of osteoprotegerin in the osteoblasts resulting in stimulation of bone resorption (Liao et al, 2002) and reduction of the life-span of osteoblasts and increase of the life-span of osteoclasts (Chen et al., 2000). 
Certain medications are in therapeutic use to prevent fractures in women with estrogen deficiency. These included estrogen replacement therapy, raloxifenc. nis:al calcitonin, biphosphonates and parathyroid hormone (Watts, 1999). Although, theoretically, the most appropriate therapy for osteoporosis in younger women is estrogen replacement therapy (Castelo-Branco, 1998; Watts, 1999), yet the trial-based evidence of the ability of hormone replacement therapy (HRT) to prevent fractures is not strong. Moreover, the menstrual bleeding and increased risk of endomctriosis. endometrial cancer and breast cancer are among the factors that lead to limitation of the use of HRT (Gibaldi, 1997; Colditz, 1998).

Carnosine (B-alanyl-L-histidine) is a dipeptide abundantly present in the skeletal muscles and in the nervous tissues of the vertebrates including humans (Boldyrev and Severin, 1990; Abe, 1991). Carnosine was proved to aid the recovery of fatigued muscle, to act as a membrane-stabilizing agent, to possess antioxidant activity and to have certain therapeutic properties (Perelman et al., 1989; MacFarlane et al., 1991; Bogardus et al., 1992). Many researches pointed to the wide safety of carnosine. No toxic effects of carnosine were observed even at concentrations of up to $500 \mathrm{mg} / \mathrm{kg}$ body weight (Frmakova et al., 1988). In addition, Soliman and Abdel Monem (2001) recorded carnosine LD 50 in mice as $18.5 \mathrm{gm}$ / $\mathrm{kg}$, a fact pointing to its safety.

A specific biological action of carnosine that may be of orthopedic importance is that it can uniquely chelate zinc ion forming B-alanyl-L-histidinato zinc (AHZ) that has more intensive effect than zinc sulfate on bone formation suggesting its role in treatment of osteoporosis (Kishi \& Yamaguchi, 1994 - a \& b; Yamaguchi, 1995; Yamaguchi \& Kishi, 1995 - a). The dipeptide of AHZ may be useful in the penetration of zinc ions into marrow cells with stimulation of the osteoblastic cells (Hashizume \& Yamaguchi, 1994; Yamaguchi et al., 1994; Yamaguchi and Matsui, 1997) and inhibition of the osteoclastic ccll formation (Yamaguchi, 1995; Yamaguchi \& Kishi, 1995 - a).

The aim of this work was to evaluate the degree of efficiency of the camosine in prevention and treatment of osteoporosis through a histological and histomorphometric study of its effect on lumbar vertebrae in ovariectomized hamsters.

\section{MATERIALS AND METHODS}

Thirty-three adult female hamsters weighing $105-120$ gms were used in this study. They were housed in cages, five animals each, under good hygienic 
conditions and food and water were allowed ad libitum. The animals were divided into four groups as follows:

( roup I (sham-operated group; control group; $\mathbf{n}=9$ ) :

the animals were subjected to sham operation by mobilizing the ovaries of both sides without doing ovariectomy.

Group II (ovariectomy only; $n=9$ ) :

bilateral ovariectomy was performed for the animals of this group.

\section{Group III (ovariectomy with early carnosine treatment; $n=9$ ) :}

bilateral ovariectomy was performed for these animals followed by a daily dose of intramuscular injection of carnosine $(10 \mathrm{mg} / \mathrm{kg}$ body weight), starting from the next day after the operation.

\section{Group IV (ovariectomy with late carnosine treatment; $n=6$ ) :}

the animals were subjected to bilateral ovariectomy. Four weeks after the operation, the animals started to receive a daily dose of intramuscular injection of carnosine ( $10 \mathrm{mg} / \mathrm{kg}$ body weight).

In each group, the animals were anaesthetized by intramuscular injection of 0.5 $\mathrm{ml}$ of sodium thiopental of concentration of $1 \mathrm{gm} / 20 \mathrm{ml}$ of distilled water and a midline abdominal incision was performed. Both ovaries were identified and mobilized with great care to avoid injuring the surrounding structures. Bilateral ovariectomy was done in groups II, III and IV. After the operation, the incision was closed by interrupted 0.5 -silk sutures and the wound was sprayed by antibiotic powder.

The animals of each group were killed - three animals at a time - by intraperitoneal injection of $1 \mathrm{ml}$ of sodium thiopental at the specified intervals of 4,6 and 8 weeks, from the date of the operation, in groups I, II and III and at intervals of 6 and 8 weeks, from the date of the operation, in group IV. The lumbar vertebrae were removed from each animal and fixed in $10 \%$ formol saline. The specimens were decalcified using $2 \%$ formic acid, and then paraffin blocks were prepared. Longitudinal sections of $7 \mu \mathrm{m}$ were cul stained with $\mathrm{Hx} \& \mathrm{E}$ and Masson's trichrome (Masson, 1924) stains.

\section{Morphometric quantification :}

The areas of bone trabeculae ( $\mathrm{Ab}$, in $\mu \mathrm{m}^{2}$ ) and their perimeters $(\mathrm{Pb}$, in $\mu \mathrm{m}$ ) were measured using the binary image of the image-analyzer computer assisted by 
the software Leica Qwin 500 with a standard measuring frame (At) of 720240.8 $\mu \mathrm{m}^{2}$. These data were measured in 10 fields of each specimen and the mean values were obtained. The following parameters were calculated using the following equations, according to Parlitt et al. (1983) :

- Trabecular bone volume (TBV) $\%=(\mathrm{Ab} / \mathrm{At}) \mathrm{X}^{\mathrm{i}} 100$.

- Mean trabecular plate thickness (MTPT; $\mu \mathrm{m})=(2.000 / 1.199) X(\mathrm{Ab} / \mathrm{Pb})$.

- Mean trabecular plate density (MTPD; per millimeter $)=(1.199 / 2.000) X(\mathrm{~Pb}$ ( At).

\section{Statistical analysis (Table) :}

The Statistical Package for the Social Sciences (SPSS version 7.5) was used in data analysis. Data were expressed as mean \pm SE. One-way analysis of variance (ANOVA) was used. The percenlage of reduction compared to the control was calculated as follows:

$\%=[($ treated-control $) /$ control $] \times 100$.

\section{RESULTS}

\section{Morphometric study (Table; Figs. 1, 2, 3) :}

In group Il, where the animals underwent ovariectomy only, the measurements of each of TBV\%, MTPD and MTPT showed reduction in their values compared with those of the control group I as well as with groups III and IV, along the whole period of the cxperiment. Comparing to the control group, the reduction in the values of TBV\% and MTPT were statistically significant $(\mathrm{P}<0.05)$, at the $4^{\text {th }}$ weck of the operation and statistically highly significant $(\mathrm{P}<0.01)$ at the other period intervals. On the other hand, the reduction in MTPD became statistically significant $(\mathrm{P}<$ $0.05)$ from the $6^{\text {th }}$ week onwards.

The measurements of TBV\%, MTPD and MTPT of group III (ovariectomy + early carnosine treatment) were higher than those of group II but still showed reduction in their values compared with the control group. The reduction of the values of measurements of MTPD was statistically insignificant $(P>0.05$ ) along the whole period of the experiment while the reduction of those of TBV\% and MTPT were statistically insignificant at the $4^{\text {th }}$ week from the date of the operation then statistically significant at the other intervals.

In group IV (ovariectomy + late carnosine treatment), the measurements of TBV\% and MTPD were higher than those of group II but lower than those of groups 
1 and III. Comparing with the control group, the reduction in the values of the measurements of TBV\% were statistically significant along the whole period of the experiment while the reduction of the measurements of MTPD were statistically significant at the $8^{\text {th }}$ week of the operation. On the other hand, the values of measurements of MTPT were higher than those of groups II and III and lower than those of group I, where the reduction was statistically significant, along the whole period of the experiment.

There was an overall variation significance among the different animal groups, which became more significant with the increased lime interval as indicated from the greater numerical value of F-ratio by the $8^{\text {th }}$ week from the date of the operation. 
Table : Measurements of the trabecular bone volume percent (TBV \%), mean trabecular plate density (MTPD / $\mathrm{mm}^{3}$ ) and mean trabecular plate thickness (MTPT, $\mu \mathrm{m}$ ) in the different experimental groups.

\begin{tabular}{|c|c|c|c|c|}
\hline weeks & Groups & $\begin{array}{c}\text { TBV \% } \\
\text { Mean } \pm \text { SE }\end{array}$ & $\begin{array}{c}\mathrm{MTPD} / \mathrm{mm}^{3} \\
\text { Mean } \pm \mathrm{SE}\end{array}$ & $\begin{array}{c}\text { MTP'I }(\mu \mathrm{m}) \\
\text { Mean } \pm \text { SE }\end{array}$ \\
\hline \multirow[t]{3}{*}{4 weeks } & Control & $42.44 \pm 2.37$ & $7.46 \pm 0.88$ & $57.43 \pm 1.52$ \\
\hline & $\begin{array}{c}\text { Group II } \\
\text { PR } \\
\end{array}$ & $\begin{array}{c}35.11 \pm 2.83 \\
(-17.27)^{*} \\
\end{array}$ & $\begin{array}{c}7.16 \pm 0.73 \\
(-4.02) \\
\end{array}$ & $\begin{array}{c}50.16 \pm 2.21 \\
(-12.66)^{*} \\
\end{array}$ \\
\hline & $\begin{array}{c}\text { Group III } \\
\text { PR } \\
\end{array}$ & $\begin{array}{c}42.09 \pm 6.17 \\
(-0.82)\end{array}$ & $\begin{array}{c}7.44 \pm 0.68 \\
(-0.26)\end{array}$ & $\begin{array}{c}55.52 \pm 3.09 \\
(-3.32)\end{array}$ \\
\hline \multicolumn{2}{|l|}{ F-ratio } & 0.47 & 0.95 & 0.27 \\
\hline \multirow{5}{*}{6 weeks } & Control & $42.44 \pm 2.37$ & $7.46 \pm 0.88$ & $57.43 \pm 2.52$ \\
\hline & $\begin{array}{c}\text { Group II } \\
\mathbf{P R}\end{array}$ & $26.33 \pm 2.70$ & $6.24 \pm 0.41$ & $41.97 \pm 2.95$ \\
\hline & & $(-37.95)^{* * *}$ & $(-16.35)^{*}$ & $(-26.91)^{* *}$ \\
\hline & $\begin{array}{c}\text { Group III } \\
\text { PR }\end{array}$ & $\begin{array}{c}32.14 \pm \overline{2.17} \\
(-24.26)^{*}\end{array}$ & $\begin{array}{c}7.18 \pm 0.50 \\
(-3.75)\end{array}$ & $\begin{array}{c}44.83 \pm 3.47 \\
(-21.39)^{*}\end{array}$ \\
\hline & $\begin{array}{c}\text { Group IV } \\
\text { PR }\end{array}$ & $\begin{array}{c}29.83 \pm 3.77 \\
(-29.71)^{*}\end{array}$ & $\begin{array}{c}6.50 \pm 0.85 \\
(-12.87)\end{array}$ & $\begin{array}{c}45.82 \pm 5.17 \\
(-20.22)^{*}\end{array}$ \\
\hline \multicolumn{2}{|l|}{ F-ratio } & 2.69 & 1.66 & $\frac{(1.20 .22)}{2.74}$ \\
\hline \multirow[t]{6}{*}{8 weeks } & Control & $42.44 \pm 2.37$ & $7.46 \pm 0.88$ & $57.43 \pm 1.52$ \\
\hline & $\begin{array}{c}\text { Group II } \\
\text { PR }\end{array}$ & $18.01 \pm 4.19$ & $\begin{array}{c}4.82 \pm 0.58 \\
(-35.38)^{*}\end{array}$ & $37.65 \pm 4.12$ \\
\hline & Group III & $\frac{(-57.56)^{* *}}{29.36 \pm 4.51}$ & $\frac{(-35.38)^{*}}{6.97 \pm 1.64}$ & $\frac{(-34.44)^{*-7}}{42.27 \pm 5.76}$ \\
\hline & PR & $(-30.82)^{*}$ & $(-6.56)$ & $(-26.39)^{*}$ \\
\hline & Group IV & $28.18 \pm 2.71$ & $5.36 \pm 0.41$ & $52.46 \pm 1.21$ \\
\hline & PR & $(-33.60)^{*}$ & $(-28.15)^{*}$ & $(-8.65)^{*}$ \\
\hline \multicolumn{2}{|l|}{ F - ratio } & $4.64 \#$ & 1.25 & $8.84 \# \#$ \\
\hline
\end{tabular}

PR : Percentage of reduction compared to the control.

SE : Standard error

* : Significant with respect to the control group $(p<0.05)$

** : Highly significant with respect to the control group $(p<0.01)$

\# : Significant at $p<0.05$ (ANOVA)

\#\# : Significant at $\mathrm{p}<0.01$ (ANOVA).

Note : The F - ratio indicates the overall significance among the different animal groups. The greater the numerical value of the $\mathrm{F}$ - ratio the more significant the difference is. 


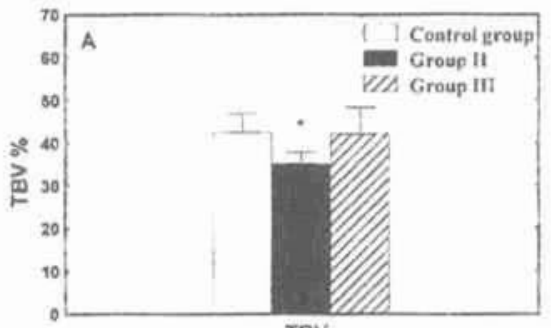

TBV
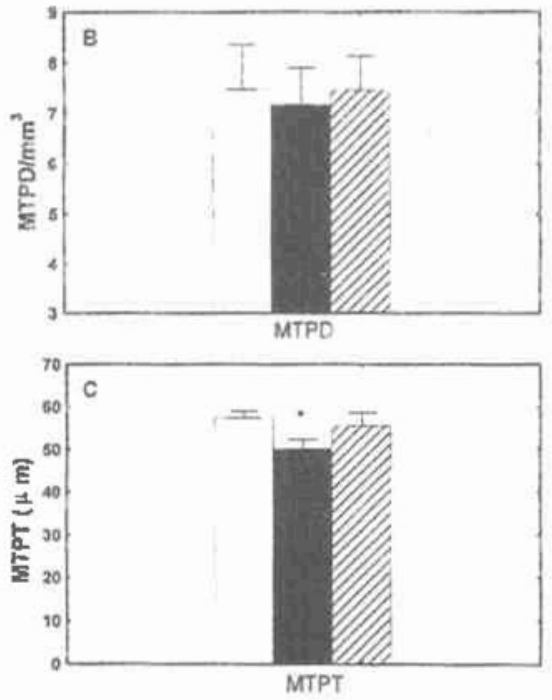

Fig (1) : A histogram showing :

A) The trabecular bone volume (TBV \%).

B) Mean trabecular plate density (MTPD $/ \mathrm{mm}^{3}$ ).

C) Mean trabecular plate thickness (MTPT, $\mu \mathrm{m}$ )

All measurements are demonstrated in the different experimental groups 4 weeks after the operation.

* Significant with respect to the control group $(p<0.05)$. 

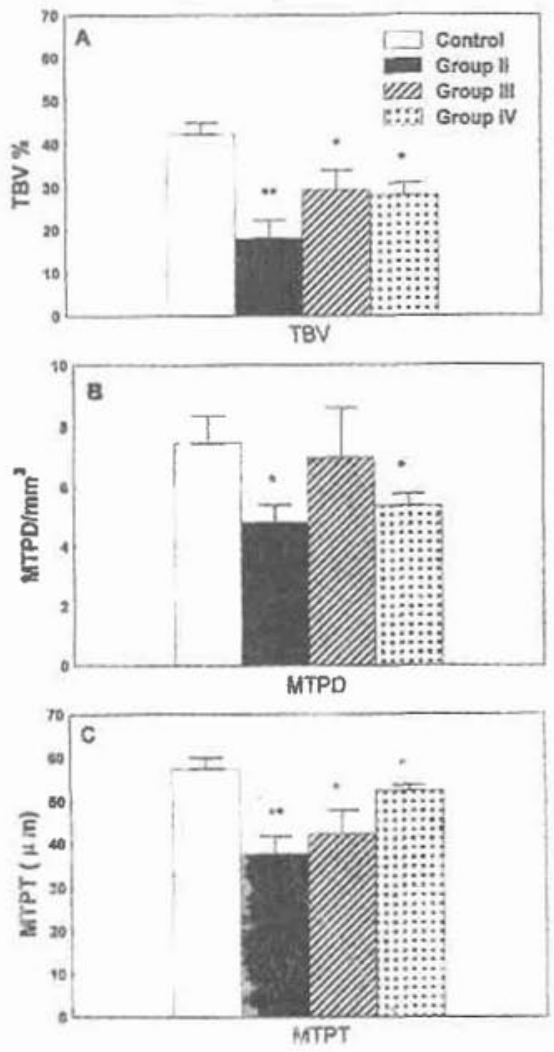

Fig (2): A histogram showing:

A) The trabecular bone volume (TBV \%).

B) Mean trabecular plate density (MTPD $/ \mathrm{mm}^{3}$ ).

C) Mean trabecular plate thickness (MTPT, $\mu \mathrm{m}$ )

All measurements are demonstrated in the different experimental groups 6 weeks after the operation.

* Significant with respect to the control group $(\mathrm{p}<0.05)$.

** Highly significant with respect to the control group $(\mathrm{p}<0.01)$. 

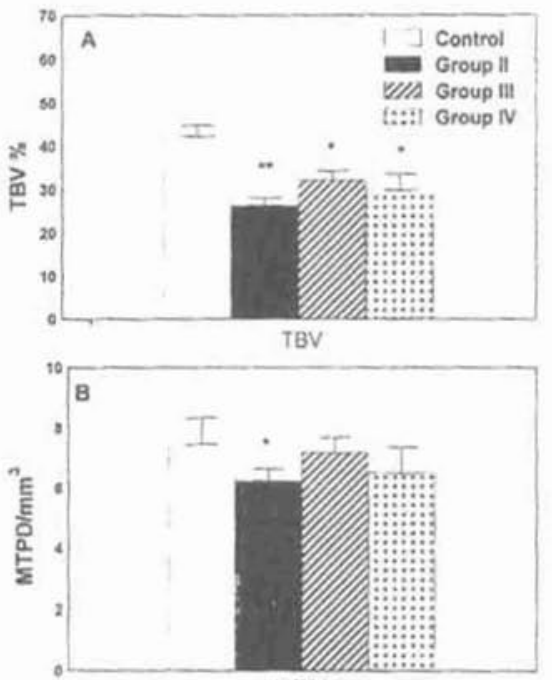

MTPD

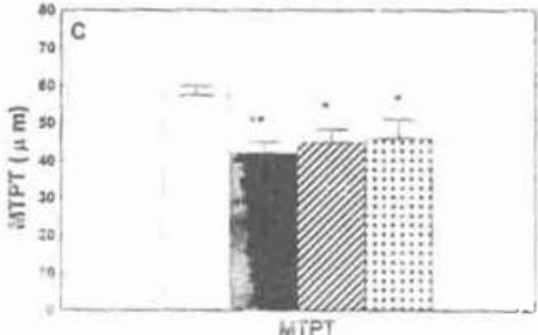

Fig (3) : A histogram showing :

A) The irabecular bone volume (TBV \%).

B) Mean trabecular plate density (MTPD $/ \mathrm{mm}^{3}$ )

C) Mean trabecular plate thickness (MTPT. $\mu \mathrm{m}$ )

All measurements are demonstrated in the different experimental groups 8 weeks after the operation.

* Significant with respect to the control group $(p<0.05)$.

** Highly significant with respect to the control group $(p<0.01)$. 
Itistulogical study :

Group I (sham-operated, control group) :

! . mpludual sections of the lumbar vertebrae showed a thick shell of compact inne with prominent Haversian system.(Fig. 4). The bone trabeculae were thick and arranged in vertical and transverse directions with good intertrabccular connectivity (Fig. 5). Well-aligned and intact cement lines could be seen in both compact and trabecular bones (Figs. 4 \& 5 ).

\section{Ovariectomized groups :}

\section{Four weeks post-operative :}

\section{* Group II (ovariectomy only) :}

The histological picture of the lumbar vertebrae of these animals showed a thin shell of compact bonc containing few osteoporotic cavities (Fig. 6). A number of osteoclasts eroding the inner aspect of the compact bone could be seen (Fig. 7). The bone trabeculae were thin and fewer in number - compared with those of the control group - and arranged mainly in a vertical direction with many free ends and decreased intertrabecular connectivity (Fig. 8). Areas containing cartilaginous matrix and cartilage cells were demonstrated in many of bone trabeculae (Figs. 8,9-a\& b). The bone marrow cavities were wide and contained a number of fat cells (Fig. 8).

\section{* Group III (ovariectomy with early carnosine treatment) :}

The lumbar vertebrae of the animals of this group showed a thick shell of compact bone with intact cement lines (Fig. 10). The bone trabeculae were thick and arranged in vertical and transverse directions with good intertrabecular connectivity (Fig. 11). The bone trabeculae demonstrated few numbers of osteoporotic cavities (Fig. 11), many osteocytes and well-formed cement lines (Fig. 12).

\section{Six weeks post-operative :}

\section{* Group II (ovariectomy only) :}

The histological picture of the lumbar vertebrae of these animals showed osteoporotic cavities within a thin shell of compact bone (Fig. 13). There were few thin bone trabeculae arranged mainly vertically with poor intertrabecular connectivity and wide bone marrow cavities (Fig. 13). Some of the trabeculae formed a thin shell around large mass of cartilage cells (Fig. 13). 


\section{* Group 111 (ovariectomy with early carnosine treatment) :}

$1 \mathrm{~h}$ lumbar vertebrae of this group showed thick bone trabeculae arranged both $s_{i 1}$ irontally and vertically with good intertrabccular connectivity (Fig. 14). Cleavige of cement line (Fig. 14) and sites of osteoporotic cavities as well as few areas of cartilaginous matrix could be seen within some bone trabeculae (Figs. 14, 15). Proliferation of the cartilaginous plate was detected (Fig. 15) indicating active process of bone formation.

\section{* Group IV (ovariectomy with late carnosine treatment) :.}

The histological picture of the lumbar vertebrae of this group showed many osteocytes within a relatively thin shell of compact bonc, compared with that of the control group, (Fig. 16). The bone trabeculae were mainly arranged in vertical direction with decreased intertrabecular connectivity. The trabeculac demonstrated cartilaginous areas as well as few osteoporotic cavities (Fig. 17).

\section{Eight weeks post-operative :}

\section{* Group Il (ovariectomy only) :}

The lumbar vertebrae of these animals still showed a thin shell of compact bone with some osteoporotic cavities. The bone trabeculae were mainly arranged vertically and showed large cartilaginous areas and sites of osteoporotic cavities. There was much reduction of the intertrabecular connectivity and increased trabecular free ends with widening of the bone marrow cavities (Fig. 18). Many osteoclastic cells were demonstrated, either imbedded inside the bone trabeculae or eroding their surfaces (Figs, 19 - a \& b).

\section{* Group III (ovariectomy with early carnosine treatment) :}

By the end of the $8^{\text {th }}$ week following the date of the operation, the compact bone shell of the lumbar vertebrae of these animals was still thick; having similar thickness to that of the control group with large number of osteocytes (Fig. 20). The bone trabeculae were arranged both vertically and horizontally with intertrabecular connectivity and few trabecular free ends. Small cartilaginous areas as well as few osteoporotic cavities could be seen within the trabecular bone (Fig. 21). Active process of bone formation was indicated by the appearance of osteocytes within the areas of the cartilaginous matrix occupying the bone trabeculae (Fig. 22). 


\section{* Group IV (ovariectomy with late carnosine treatment) :}

The histological picture of the lumbar vertebrae of these animals showed bone trabeculae arranged mainly vertically and decreased intertrabecular connectivity with few trabecular free ends. Small areas of cartilaginous matrix and several osteoporotic cavities were also demonstrated within the bone trabeculae (Fig. 23). Similar to those of group III, osteocytes were seen within the areas of cartilaginous matrix occupying the bone trabeculac.

Fig. (4) : A photomicrograph of a longitudinal section in a lumbar vertebra of group I (control group) showing thick shell of compact bone with prominent Haversian system $(\mathrm{H})$ and wellaligned cement lines (arrows). Note the covering periosteum (crossed arrow).

(Hx. \& E.; x 100)

Fig. (5) : A photomicrograph of a longitudinal section in a lumbar vertebra of group I (control group) showing thick bone trabeculae arranged in vertical and transverse directions (TB) and demonstrating intact cement line (arrow) with well intertratecular connectivity.

(IIx. \& E.; x 40)

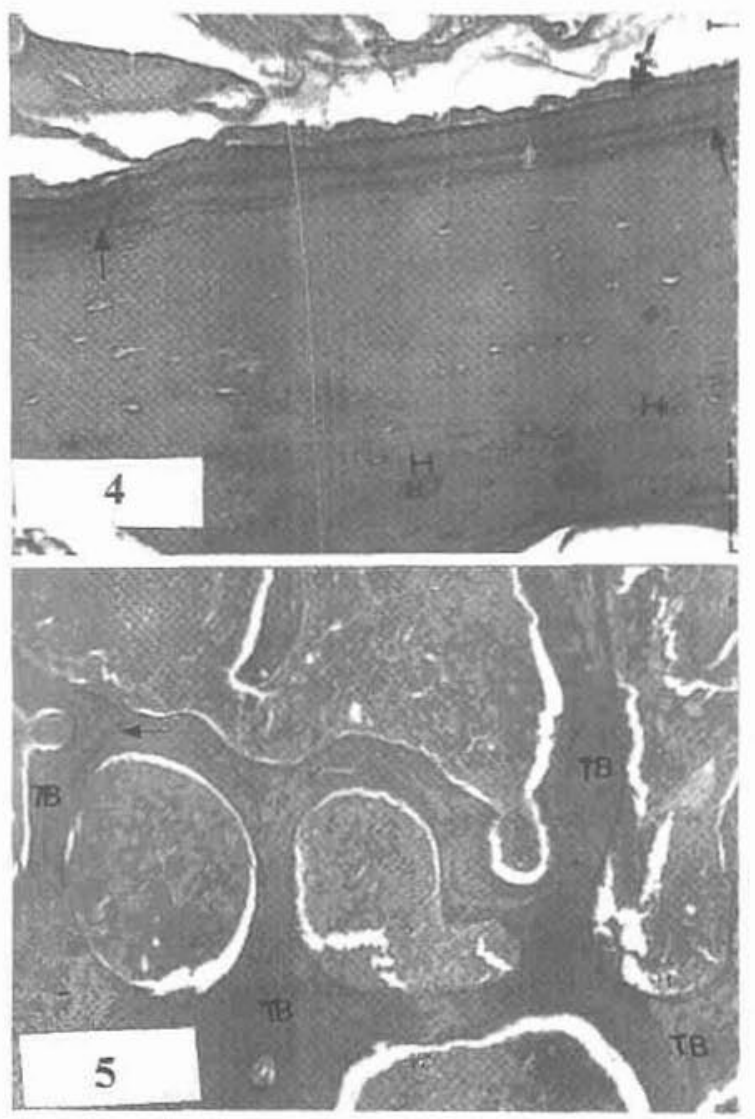



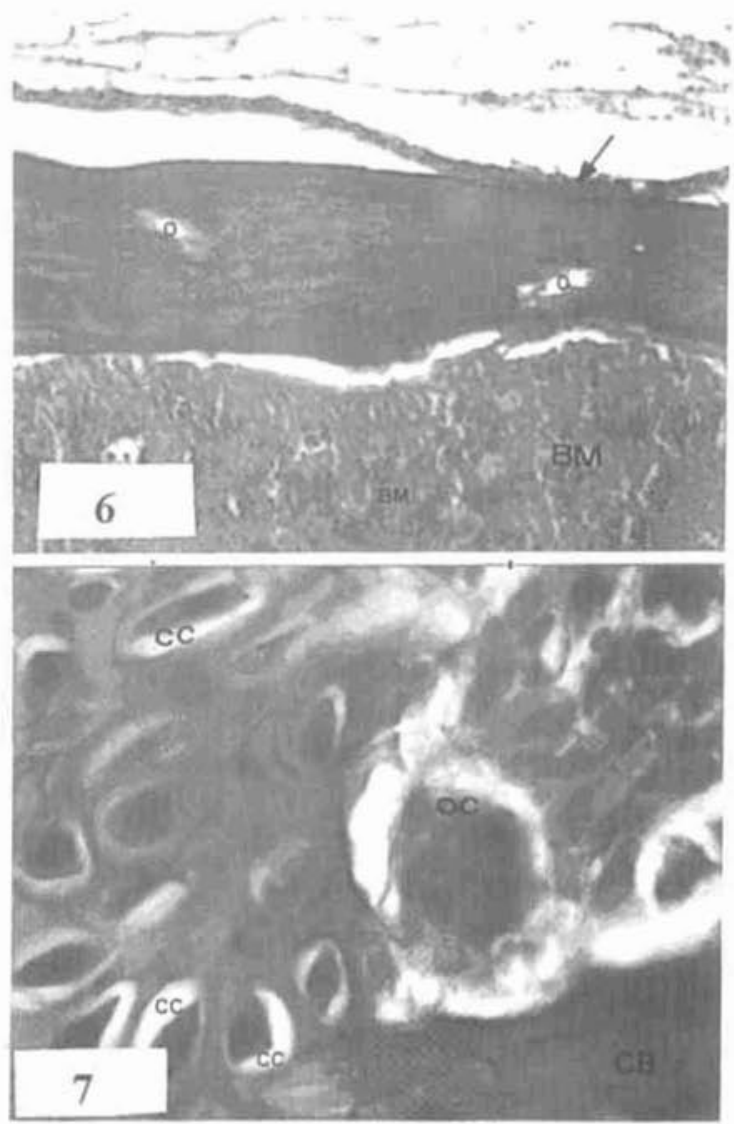

Fig. (6) : A photomicrograph of a longitudinal section in a lumbar vertebra of group II (underwent ovariectomy only), 4 weeks after the operation. showing thin shell of compact bone containing osteoporotic cavities (o). Note the periostial-covering layer (arrow).

(Iix. \& E.; x 100)

Fig. (7) : A photomicrograph of a longitudinal section in a lumbar vertebra of group II (underwent ovariectomy only), 4 weeks after the operation, showing an osteoclast $(\mathrm{OC})$ eroding the inner aspect of the compact bone (CB). Note the cartilage cells (CC) within a bone trabecula on the left side of the picture.

(Hx. \& E.; x 400) 


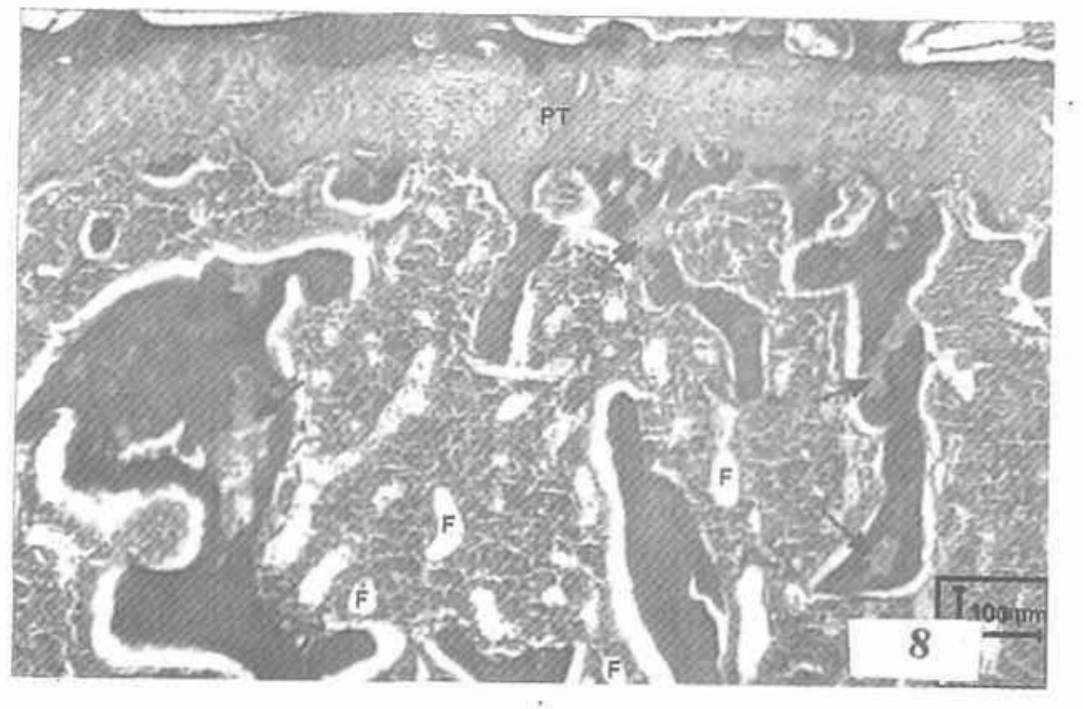

Fig. (8) : A photomicrograph of a longitudinal section in a lumbar vertebra of group II (underwent ovariectomy only), 4 weeks after the operation, showing thin bone trabeculae which are few in number and arranged mainly in a vertical direction with many trabecular free ends. Decreased trabecular connectivity and areas containing cartilaginous matrix (arrows) within the bone trabeculae are clearly seen. Note the wide bone marrow cavities containing a number of fat cells (F) and the cartilaginous plate (PT).

(Hx. \& B.; x 40) 

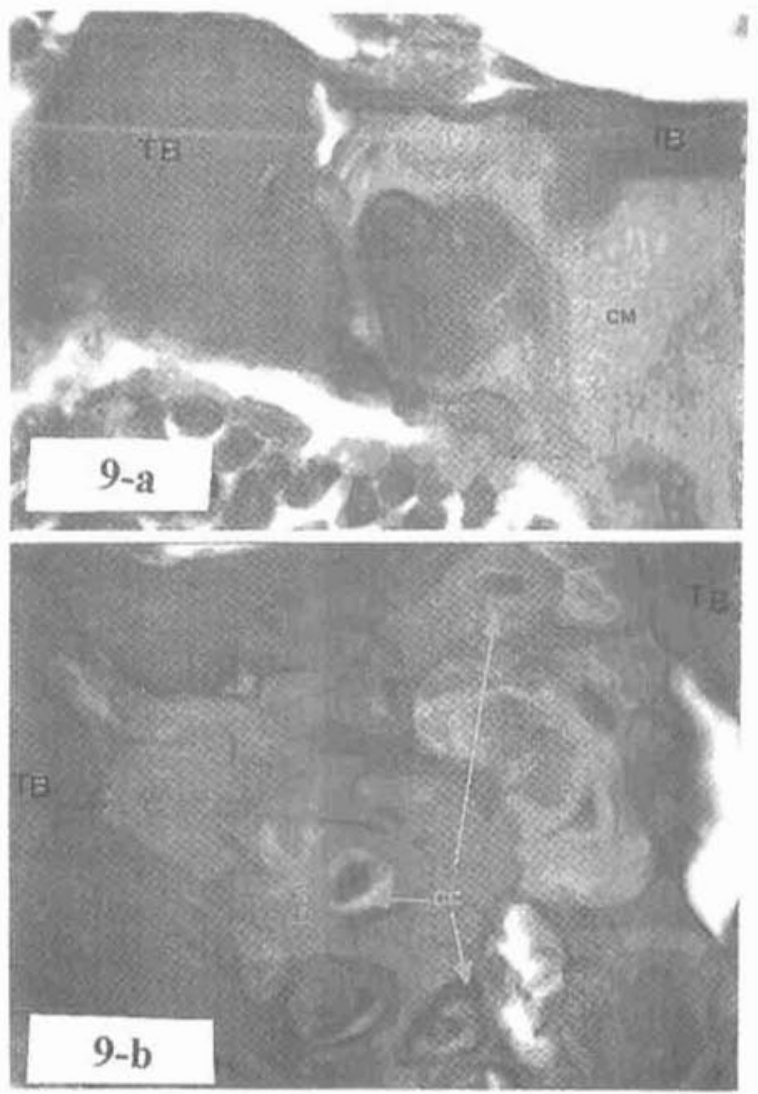

Figs. (9 a \& b) : Photomicrographs of different fields of a longitudinal section in a lumbar vertebra of group II (underwent ovariectomy only), 4 weeks after the operation, showing :

a) Cartilage matrix $(\mathrm{CM})$ within a bone trabecula (TB).

b) Cartilage cells (CC) within a bone trabecula (TB).

(Hx. \& E.; $\times 400)$

(Hx. \& E.; $\times 400)$ 

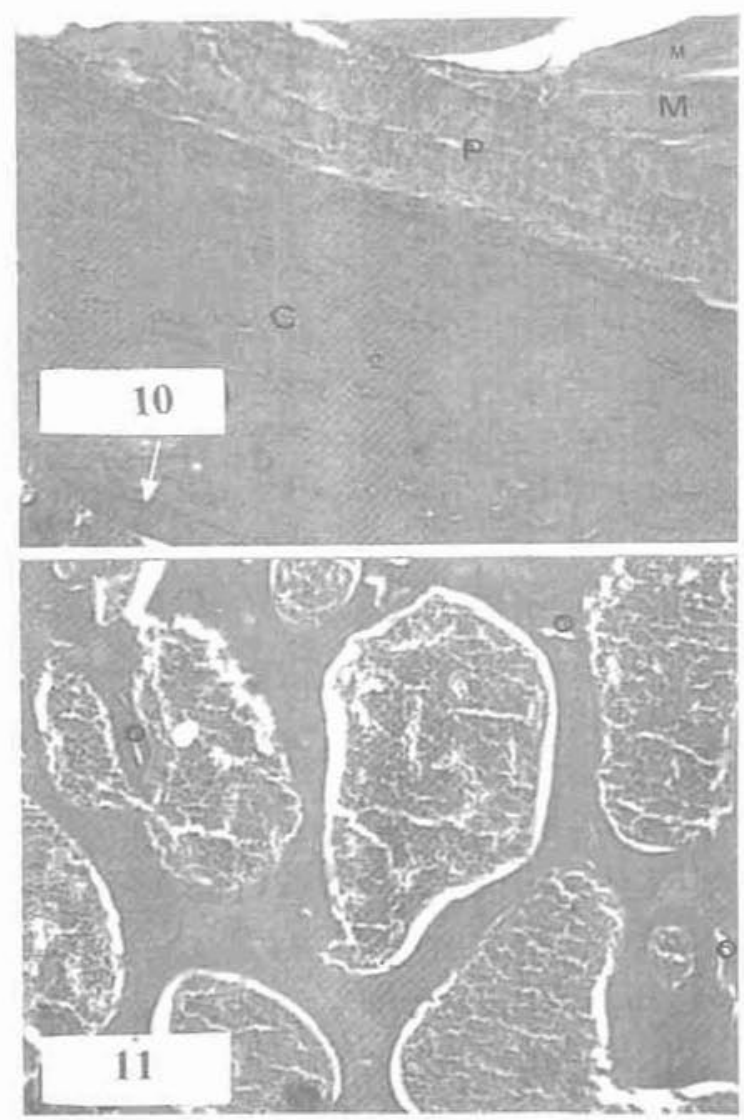

Fig. (10) : A photonicrograph of a longitudinal section in a lumbar vertebra of group III (underwent ovariectomy with early camosine treatment). 4 weeks after the operation, showing a thick shell of compact bone (C) with intact cement line (arrow). Note the thick covering layer of periosteum (P) with muscle fibers $(\mathrm{M})$ antached to it.

(Hx. \& E.; x 100)

Fig. (11) : A photomicrograph of a longitudinal section in a lumbar vertebra of group III (underwent ovariectomy with early camosine trealment). 4 weeks after the operation, showing thick bone trabeculae arranged in verti$\mathrm{cal}$ and transverse directions with good intertrabecular connectivity. Few osteoporotic cavities (o) can be seen within the bone trabeculae.

(Hx.\& E.; x 40) 


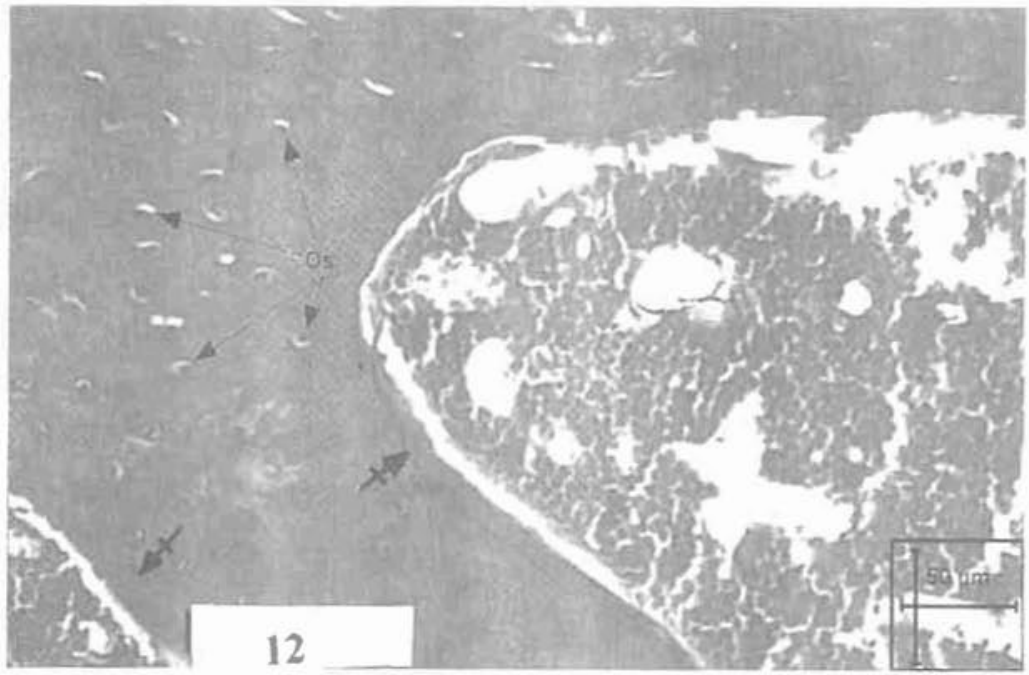

Fig. (12) : A photomicrograph of a longitudinal section in a lumbar vertebra of group III (underwent ovariectomy with early camosine treatment), 4 weeks after the operation, showing one of the bone trabeculae with many osteocytes (os) and intact cement lines (crossed arrows).

(Hx. \& E.; x 100)

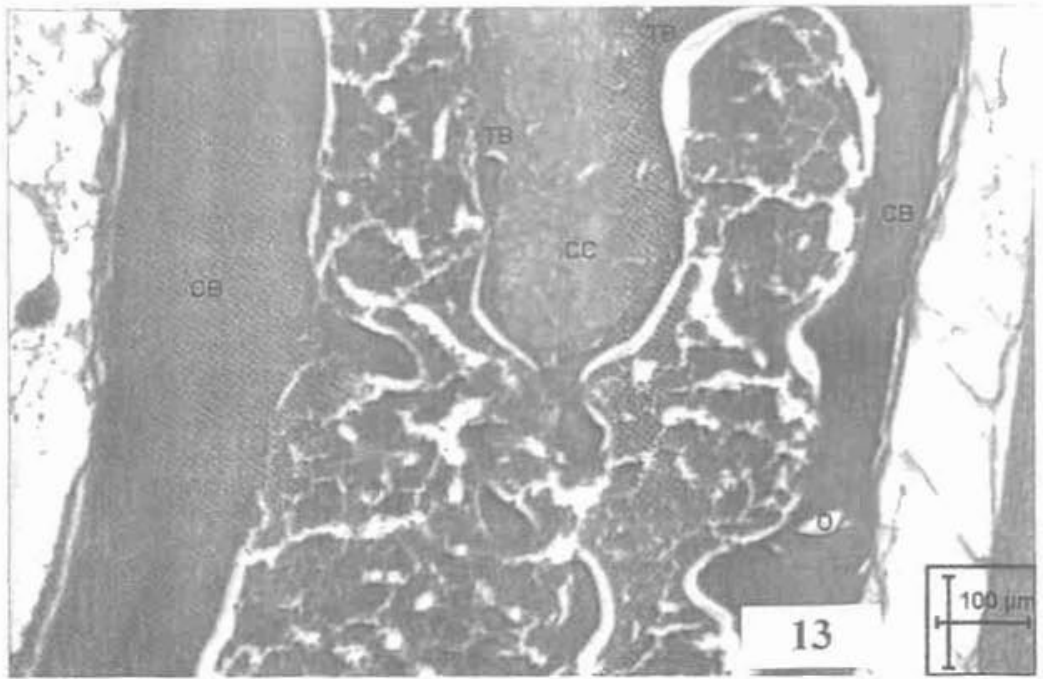

Fig. (13) : A photomicrograph of a longitudinal section in a lumbar vertebra of group II (underwent ovariectomy only), 6 weeks after the operation, showing an osteoporotic cavity (o) within a thin shell of compact bone (CB). Few thin bone trabeculae arranged mainly in vertical dinection with poor intetrabecular connectivity and wide bone marrow cavities can be seen. Note the thin layer of trabecular bone (TB) surrounding a large mass of cartilage cells (CC).

(Hx. \& E.; x 40) 


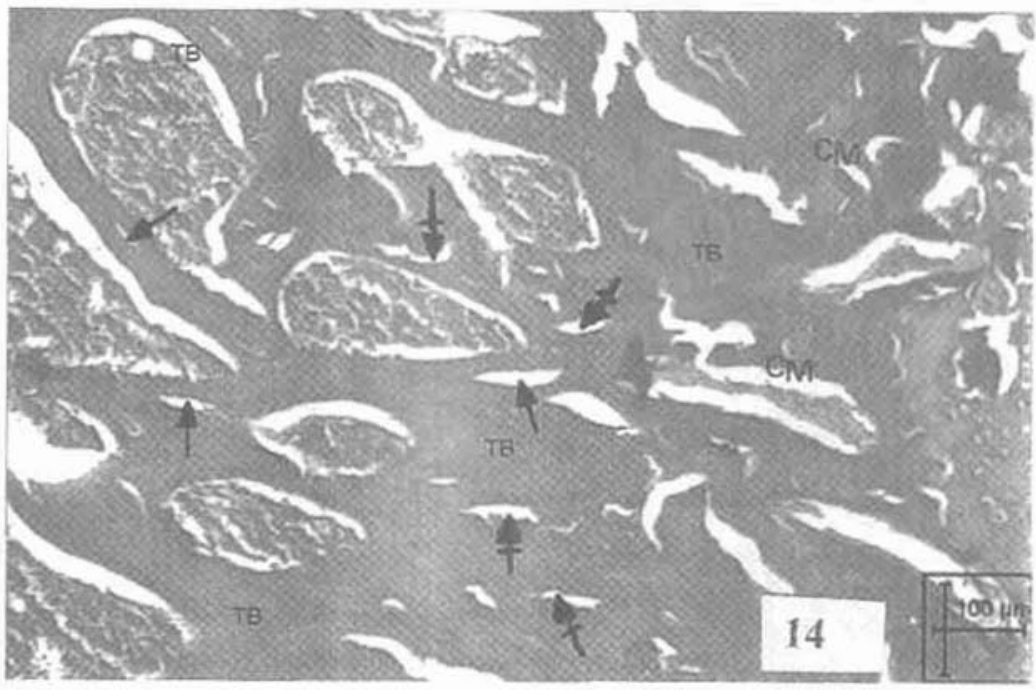

Fig. (14) : A photomicrograph of a longitudinal section in a lumbar vertebra of group III (underwent ovariectomy with early carnosine treatment), 6 weeks after the opcration, showing thick tone trabeculae arranged in transverse and vertical directions with good intertrabecular connectivity. Osteoporotic cavities (crossed arrows), cleavage of cement lines (arrows) and few areas of cartilaginous matrix (CM) can be clearly seen within the bone trabeculae.

(Hx. \& E.; x 40)

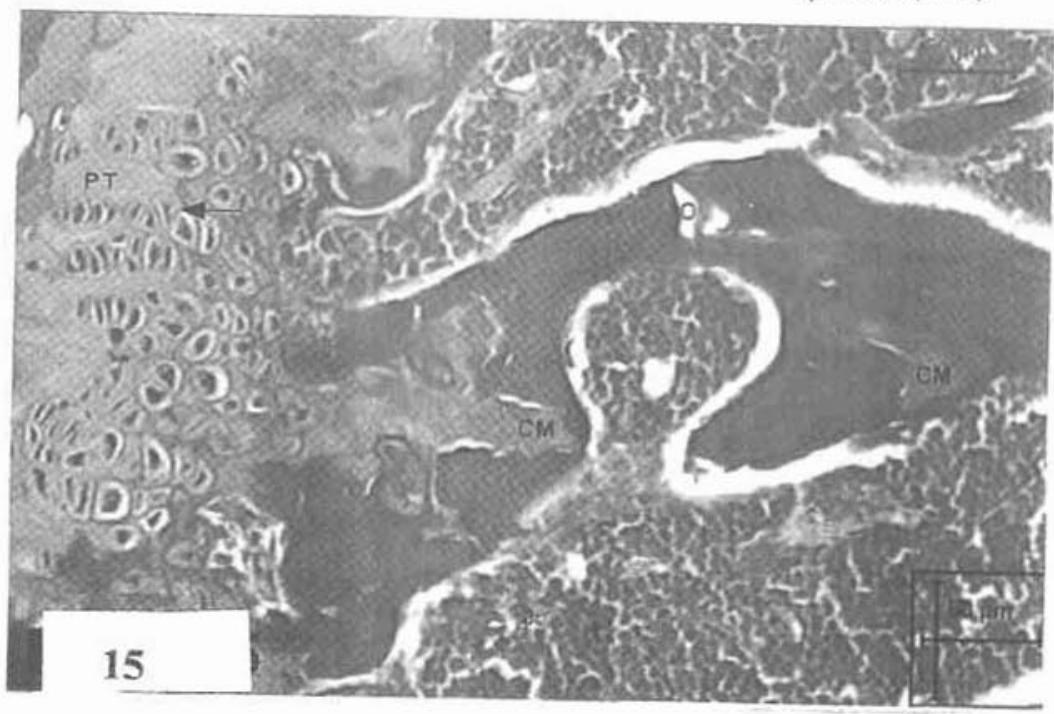

Fig. (15) : A photonicrograph of a longitudinal section in a lumbar vertebra of group III (underwent ovariectomy with early camosine treatment), 6 weeks after the operation, showing proliferation of the cartilaginous plate (PT). Note the osteoporotic cavity (o) and areas of cartilaginous matrix $(\mathrm{CM})$ within a bone trabecula.

(Hx. \& E.; x 100) 


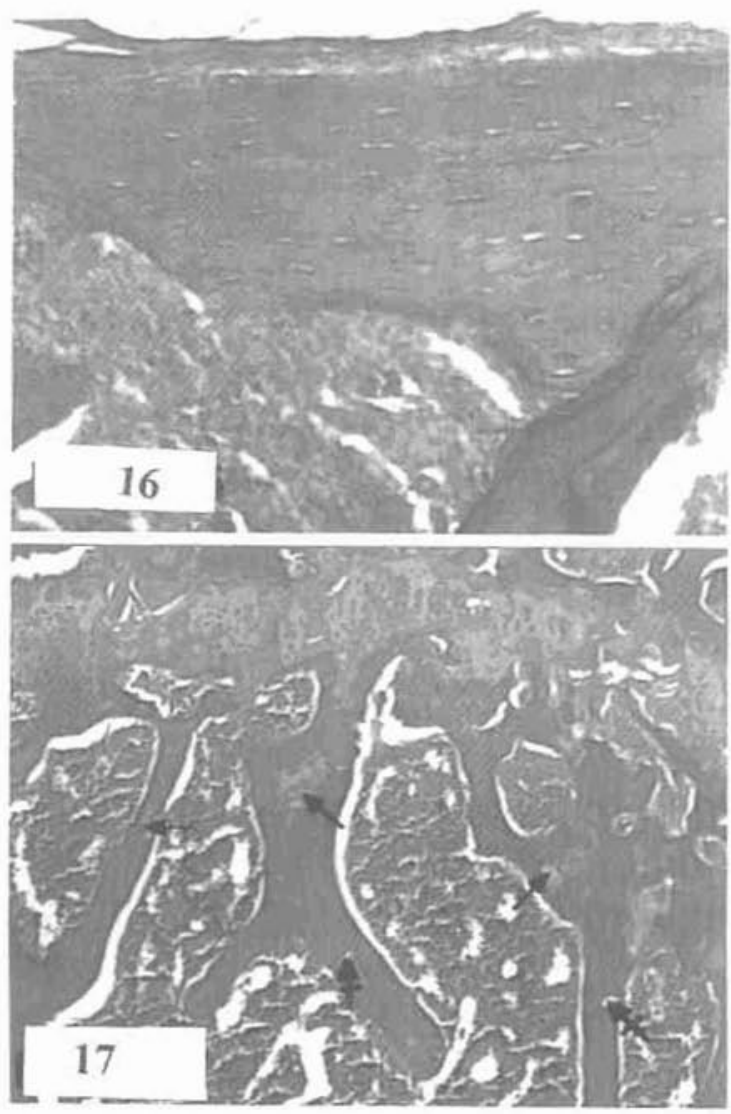

Fig. (16) : A photomicrograph of a longitudinal section in a lumbar vertebra of group IV (underwent ovariectomy with late camosine treatment), 6 weeks after the operation, showing large number of osteocyles within a relatively thin shell of compact bone.

(Hx. \& E.; x 100)

Fig. (17) : A photomicrograph of a longitudinal section in a lumbar vertebra of group IV (underwent ovaricctomy with late camosine treatment), 6 weeks after the operation, showing bone trabeculae arranged mainly in a vertical direction and containing cartilaginous areas (arrows) and few osteoporotic cavities (crossed arrows). Note the decreased intertrabecular connectivity.

(Hx. \& E.; x 40) 


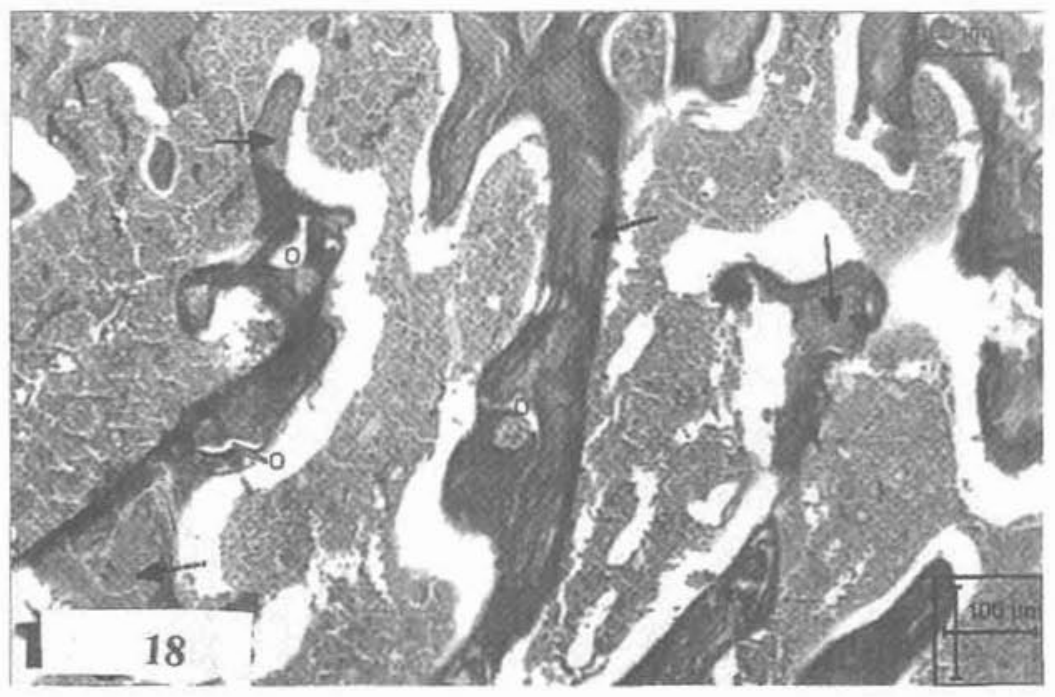

Fig. (18) : A photomicrograph of a longitudinal section in a lumbar vertebra of group II (underwent ovariectomy only), 8 weeks after the operation. The bone trabeculae are arranged mainly in a vertical direction and showed large cartilaginous areas (arrows) and sites of osteoporotic cavities (o). Much reduction of the intertrabecular connectivity, increased trabecular free ends and widening of the bone marrow cavities can be seen clearly.

(Masson's trichrome; $\mathrm{x} 40$ ) 

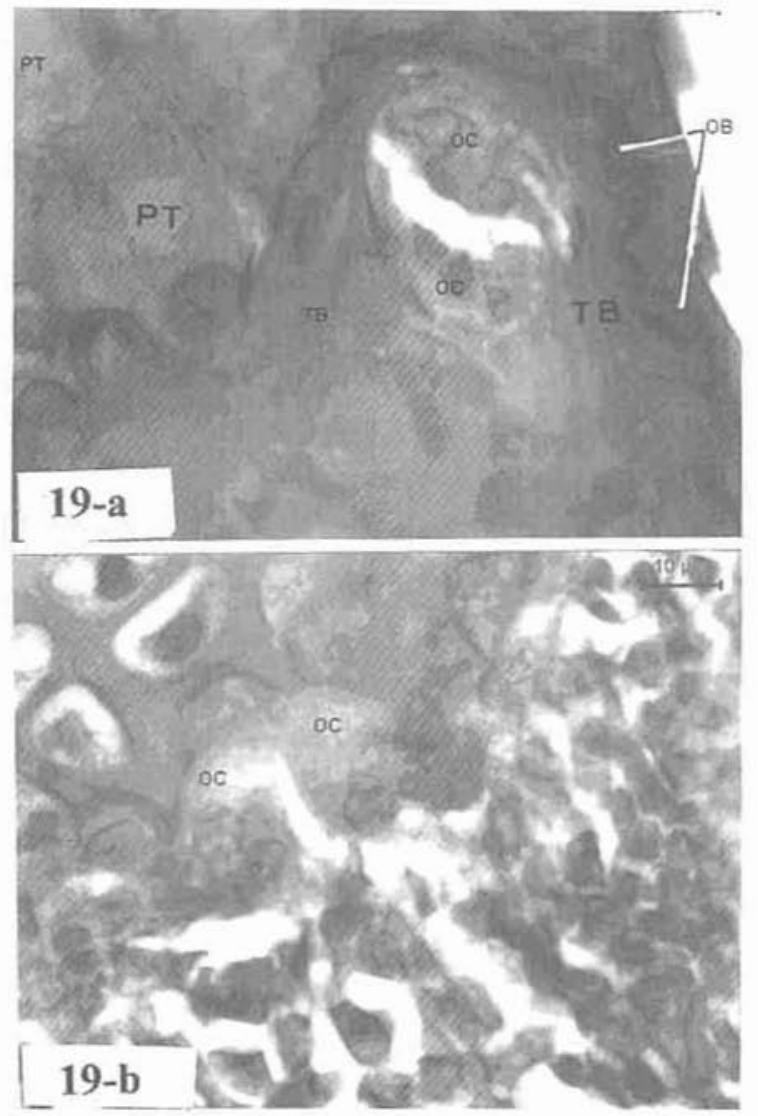

Figs. (19 a \& b) : Photomicrographs of different fields of a longitudinal section of a lumbar vertebra of group II (underwent ovariectomy only), 8 wecks after the operalion, showing :

a) Osteoclast cells $(\alpha)$ embedded inside a bone trabecula (TB). Note the osteoblasts $(\mathrm{OB})$ on the surface of the bone trabecula and the part of the cartilaginous plate (PT).

(Hx. \& E.; x 400)

b) Osteoclast cells (oc) eroding a cartilaginous surface of a bone trabecula.

(Hx. \& E.; x 400) 

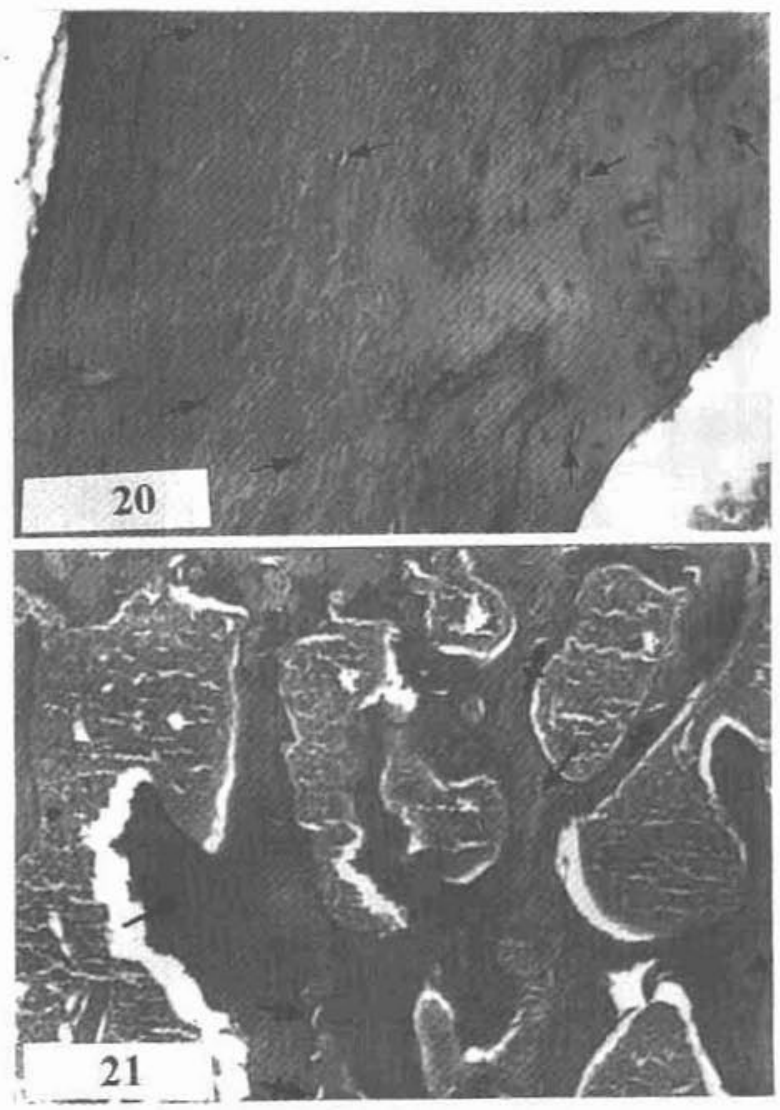

Fig. (20) : A photomicrograph of a longitudinal section in a lumbar vertebra of group III (underwent ovariectomy with early camosine treatment), 8 weeks after the operation, showing a thick shell of compact bone with large number of osteocytes (arrows).

(Hx. \& E.; x 100)

Fig. (21) : A photomicrograph of a longitudinal section in a lumbar vertebra of group III (underwent ovariectomy with early camosine treatment), 8 wecks after the operation, showing bone trabeculae arranged in both verti$\mathrm{cal}$ and horizontal directions with intertrabecular connectivity and few trabecular free ends. Small cartilaginous areas (arrows) as well as osteoporotic cavities (crossed arrows) can be seen within the bone trabeculae.

(Hx. \& E.; x 40) 


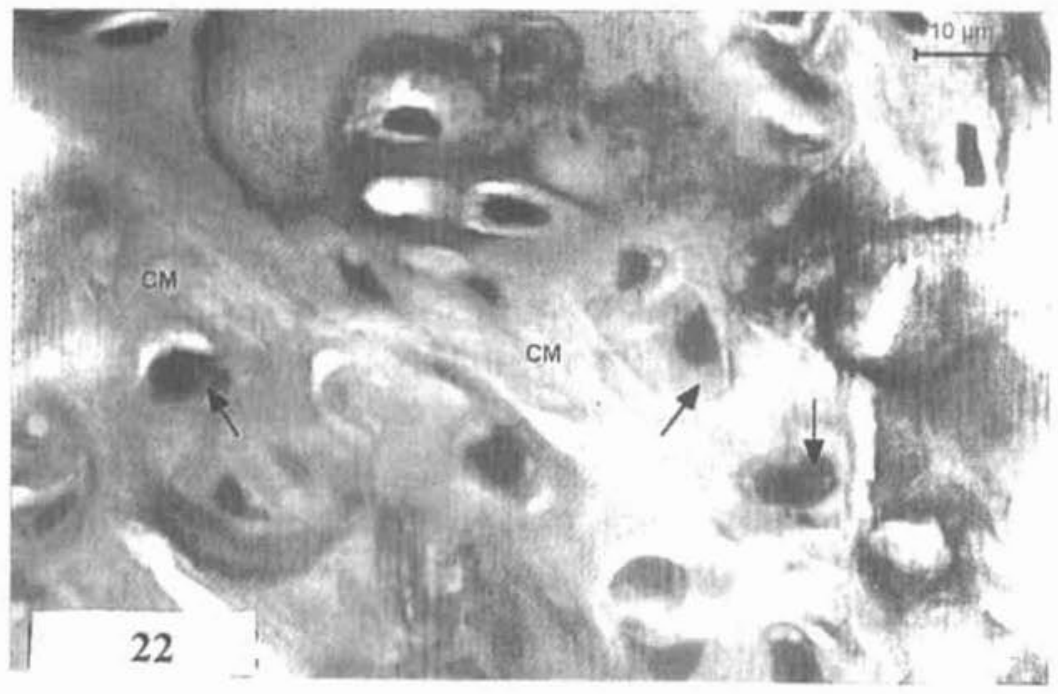

Fig. (22) : A higher magnification of a different field of the previous section showing osteocytes (arrows) within a cartilaginous area (CM) occupying one of the bonc trabeculae.

(Hx. \& E.; x 400)

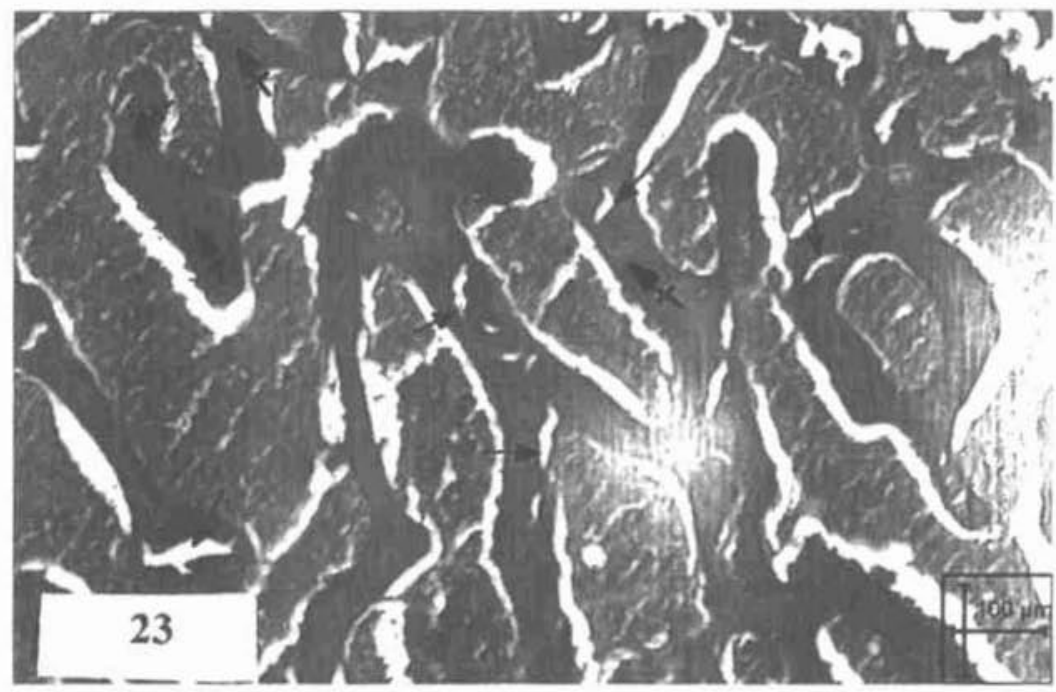

Flg. (23) : A photomicrograph of a longitudinal section in a lumbar vertebra of group IV (underwent ovariectomy with late camosine treatment), 8 weeks after the operation, showing bone trabeculae arranged mainly vertically. Small cartilagimus areas (crossed arrows) and several osteoporotic cavities (arrows) can be seen within the bone trabeculae. Note the decreased intertrabecular connectivity and the few tra. becular free ends.

(Hx. \& E.; x 40) 


\section{DISCUSSION}

Bone loss already occurs in young adult women or men. However, the rate of loss is slow because the remodeling rate is low in this young age while the loss accelcrates in women at menopause because the remodeling intensity increases and the number of basic multicellular units becomes more negative with reduction of the mineral content of bone tissue (Riggs, 2002).

In the present work, bilateral ovaricctomy flared up osteoporotic changes which, to a great extent, imitated the senile and postmenopausal osteoporotic alteration. The operation led to cancellous as well as compact bone loss of the lumbar vertebrae and its severity increased with time lapse. The compact bone showed cnhanced endocortical resorption as well as increased intracortical porosity. In agreement, Vaananen and Harkonen (1996) studying the effect of estrogen deficiency on young skcletons as well as on those following menopause, obtained the same findings. Furthermore, Vaananen and Harkonen (1996) cmphasized that the endocortical resorption represented the first response of estrogen withdrawal and preceded the intracortical porosity. In the untrcated ovariectomized animals (group II) of the current work, the presence of a few number of intracortical osteoporotic cavities with the carly appearance of the ostecclasts eroding the inner surface of the compact bone resulting in its considerable thinning, 4 wecks post-operatively, confirms this view of Vaananen and Harkonen (1996). Concerning the concellous bone, the vertically directed thin bone trabeculae containing many osteoporotic cavities with loss of the intertrabecular connectivity, the increased trabecular free ends and the widening of the bone marrow cavities were the common histological findings and were equivalent to those obtained by Chow et al. (1992), Vaananen and Harkonen (1996), Kinney et al. (1998) and Chen et al. (2000). These previous researches pointed out that the decrease in the amount of the trabecular bone and their interconnection was the most serious manifestation of estrogen loss. They, further, attributed the decreased bone mass and reduced bone strength to this disturbed bone architecture because of penetrative bone resorption and microfractures.

With time lapse after ovariectomy, it was obvious that cancellous bone was much more affected than the compact one. This finding is consistent with the statement of World Health organization (1994) rcporting that bone loss in postmenopausal osteoporosis was much slower in the cortical than the trabecular bone. Riggs et al. (1998) also assumed that there was a profound and accelerated bone loss mainly in cancellous bone during the first postmenopausal decade. Further, Riggs (2002) 
correlated this bonc loss to the abrupt loss of action of estrogen and the loss of its direct restraining effect on bone cell function.

Many mechanisms have been suggested for the development of osteoporosis following estrogen withdrawal. Vaananen and Harkonen (1996) attributed it mainly to increased osteoclast formation, whereas, Turner et al. (1987) and Wronski et al. (1988) postulated that the bone loss was the sequence of an increase in bone resorption associated with a slight increase in bone formation. Further, Sun et al. (1997), Chen et al. (2000) and Seifert-Klauss et al. (2002) ascribed the osteoporotic changes following estrogen withdrawal to inhibition of osteobalstic formation and stimulation of osteoclastic activity. Riggs (2002) pointed out that estrogen deficiency reduced osteoblast life-span and increased osteoclast life-span as well as reduced the mineral content of bone tissue. An additional statement by Seifert-Klauss et al. (2002) postulated that decreased bone formation may precede increased bone resorption. Comparable findings were previously presented by Gibaldi (1997) who deduced that estrogen withdrawal following ovariectomy induced a four-fold increase in the osteoclasts which erode the bone trabeculae leading to their perforation and eventually to their fading. This postulation perfeclly explains the present increased number of osteoclasts eroding both the compact and trabecular bones as well as the marked reduction in the bone trabecular interconnection, density and thickness observed in the ovariectomized animals (group II). The increased activity of the osteoclasts as result of estrogen withdrawal was explained by Vaananen and Harkonen (1996) who suggested that estrogen withdrawal stimulates the production of bone resorbing cytokines which regulate osteoclast formation in the bone marrow microenvironment. However, Liao et al. (2002) attributed this to the reduction of the osteoprotegerin in the osteoblasts which has an inhibitory effect on bone resorption. In these ovariectomized animal specimens, the presence of large areas of cartilaginous matrix occupying the bone trabeculae with absence of signs of active process of bone formation are in favor of the assumption that estrogen withdrawal leads, as well, to inhibition of osteoblastic activity and bone formation (Sun et al., 1997; Chen et al., 2000; Seifert-Klauss et al., 2002). Whether the effect of estrogen on osteoblasts is by direct mechanisms is still uncertain (Vaananen and Harkonen, 1996).

In group III (early carnosine-treated animals), the large number of osteocytes within a thick shell of compact bone as well as the presence of thick bone trabeculae arranged both vertically and horizontally with good intertrabecular connections denoted the role of early treatment with carnosine following ovariectomy, in 
conserving the normal bone architecture compared with those without 11. ilment (group II). Equivalent observations were presented by Yamaguchi and hishi (1993), Kishi and Yamaguchi (1994 - b) and Kishi et al. (1994). Yamaguchi and Kishi (1993) pointed out that prolonged administration of tested doses $11,11.30$, $100 \mathrm{mg} / \mathrm{kg} / \mathrm{d}$ ) carnosine could completely prevent bonc loss in the ovariectommact rats. Morcover, the histomorphological sludy of Kishi et al. (1994) supported this view. In the current work, the presence of sites of clcavage of cement linc's and osteoporotic cavities in the trabecular bone as well as reduction in TBV \% demonstrated in carnosine-treated groups might contradict the view of Yamaguchi and Kishi (1993) of a complete preventive effect of carnosine on bone loss. However, the short-term administration of carnosine ( 8 weeks) and the use of its lowest tested dose $(10 \mathrm{mg} / \mathrm{kg} / \mathrm{d})$ can explain this contradiction. In agrcement, Kishi and Yamaguchi (1994 - b) deduced that the osteoporotic preventive effect of carnosine was concentration dependent.

Yamaguchi et al. (1994), Yamaguchi and Hashizume (1994 - a \& b) and Sugiyama et al. (2000) found that beta-alanyl-L-histidine, which chelates zinc ions in various essential traces forming bcta-alanyl-L-histidinato-zinc ( $\mathrm{AHZ}$ ), prevents bone loss following estrogen withdrawal through stimulation of bone formation and osteoblastic proliferation. Segawa et al. (1993), Yamaguchi and Kishi (1993), and Yamaguchi and Kishi (1994 - a \& b) concluded that AHZ prevented deterioration of bone metabolism following ovariectomy by inhibiting the reduction of calcium and inorganic phosphorus concentrations in the serum as well as inhibiting the reduction of the alkaline phosphatase activity and calcium content of bone induced by various bone resorption factors. Further, Segawa et al. (1992) emphasized the ability of $\mathrm{AHZ}$ to prevent the development of detcriorating bone metabolism even in rats fed on low calcium and vitamin D-deficient dicts. In the current work, the presence of large number of osteocytes within both compact and trabecular bones and signs of an active process of bone formation; prolifcration of the cartilaginous plate and appearance of osteocytes within the cartilaginous areas of the bone trabeculae in carnosine treated groups are consistent with the postulation of the stimulatory effect of carnosine on bone formation.

The mechanism by which carnosine stimulates bone formation was proved by the finding of increased osteoblastic cell number, DNA content and protein concentration in the cells (Yamaguchi and Matsui, 1996). Furthermore, Soliman and Ali (2003) demonstrated that carnosine causes increase of the concentration of liver DNA and RNA as well as selective increase of serum proteins. This may add further 
support to the possible ability of carnosine to stimulate bone protein building. The intermediary metabolism involved in this carnosine stimulatory action is through its ducet effect on many cellular enzymes e.g. cellular alkaline phosphatase and protein kinase (Hashizume and Yamaguchi, 1994; Yamaguchi and Ehara, 1996; Yamaguchi and Matsui, 1997) and not through its inhibition to the effect of bone resorbing factors on osteoblastic cells (Yamaguchi and Hashizume, 1994 - a). In agreement, Yamaguchi and Hashizume (1994 - b) detected a marked increase in the concentrations of many cellular proteins, such as osteocalcin. insulin-like growth factor-1 and transforming growth factor-beta, secreted from osteoblastic cells in the culture medium by the presence of AHZ. Furthermore, Hashizume and Yamaguchi (1994) and Yamaguchi et al. (1994) demonstrated that the other zinc-chelating compounds do not have an effect on cellular protein content. They altributed the potency of AHZ on this aspect to its dipeptide part (AH: carnosine) that may be useful in the penetration of zinc ions into marrow cells stimulating their protein synthesis.

In the current histological study, failure to detect any osteoclasts on the surfaces or within the compact or the trabecular bones in the two groups treated with carnosine (III \& IV) versus to detection of many of them eroding the compact and trabecular bone in the untreated group (II), can lead to the assumption that carnosine may inhibit the osteoclastic bone resomption following estrogen withdrawal. Such assumption is in a full agreement with Kishi and Yamaguchi (1994 - a), Yamaguchi (1995) and Yamaguchi and Kishi (1996) who ascribed this phenomenon to the inhibitory effect of carnosine $\mathrm{Zn}$ compound (AHZ) on osteoclast-like cell formation, in mouse marrow culture in vitro, at the earlier stage of differentiation of marrow cells without affection of the osteoclastic number. In addition, Yamaguchi and Kishi (1995 - b) indicated that the transforming growth factor-beta has a stimulatory and an inhibitory effect on osteoclast-like cell formation in mouse marrow culture and that AHZ inhibited its stimulatory effect. Furthermore. Yamaguchi (1995) and Yamaguchi and Kishi (1995 - a) deduced that the preventive effect of AHZ on bone resorption in vivo is via its inhibitory action on the process of parathyroid hormone-induced protein kinase $\mathrm{C}$ activation. which increases the released cytoplasmic $\mathrm{Ca}^{+2}$ from its osteoclastic cell stores. The more intensive effect of AHZ than other zinc-chelating compounds was proved by Kishi and Yamaguchi (1994 - a) and Yamaguchi and Kishi (1995 - a and 1996) who attributed it to the beneficial cffect of the dipeptule component of $\mathrm{AHZ}$ in the penetration of zinc ion into marrow cells inlluencing the process of protcin kinase $\mathrm{C}$ activation.

From the presin histomorphometric study, it was found that comparing with early carnosine treated group (III), the late carnosine treated animals (group IV) 
showed an increase of the MTPT and a reduction of the MTPD, endorsed histologically with the decreased intertrabecular connectivity and the increased trabecular free ends. This findings support the view of Parfitt et al. (1983) who stated that the reduction of TBV as result of estrogen withdrawal occurs predominantly by a process that removes entire structural clements of bone rcsulting in reduction of the number of bone trabeculae (MTPD) with slight reduction of their thickness (MTPT) and converting the continuous trabecular network into a discontinuous one. They added that an increase in TBV as a result of the treatment of osteoporosis can occur by a compensatory increase in the thickness of the cxisting trabeculae without restoring the lost ones, which formation stops after fusion of the epiphyseal plate i.c. once trabecular plates lost, they can never be replaced. Furthermorc, Lane et al. (1999), and Jerome et al. (2001) pointed out that the compression strength of trabecular bone depends more on the preservation of connections between the structural elements than on the amount of bone present. They added that the thickened trabeculae produced by treatment remain disconnected, so that increasing TBV even to normal may not restore a biomechanically normal skcleton. Consequently, Lane et al. (1999) deduced that prevention of bone loss is much more important than attempting to repair the damage, once it has occurred, suggesting a prompt intervention with anti-resorptive agents for preservation of the biomechanical features of the bone.

From the present work, it is concluded that bilateral ovariectomy results in increase of osteoclastic resorption activity and inhibition of osteoblastic bone formation with destruction of bone architccture and that carnosine has both a stimulatory effect on bone formation as well as an inhibitory effect on bone resorption suggesting its role as a pharmacological tool in treatment of osteoporosis. The early carnosine intervention is advisable for preservation of the normal bone structural elements. The complete osteoporotic preventive effect of higher doses of carnosine needs further study.

\section{SUMMARY}

Four groups of adult female hamsters were used in this study, group I (control group) exposed to sham operation, group II subjected to bilateral ovariectomy, group III exposed to bilateral ovariectomy followed - next day - by a daily dose of intramascular injection of carnosine and group IV subjected to bilateral ovariectomy followed - 4 weeks later - by a daily carnosine treatment. 
The animals of groups I, II and III were sacrificed at intervals of 4, 6 and 8 14: $i h$ s while those of group IV were sacrificed at intervals of 6 and a wiks from the Jate of the operation. The lumbar vertebrae were remoced and preparcd for histomorphometric and histological study. The histomorphometric quatuification of lumbar vertebrae showed variable and statistically significant reduction of IIRV $\boldsymbol{c}_{\text {. }}$ MTPD and MTPT in animals of groups II, III, and IV. However, The highest redu tion was in the animals exposed to bilateral ovariectomy only (group II). In carly carnosine-treated group (III), the values of TBV \%, MTPD were higher and those of the MTPT were lower than the corresponding values in late (allinite-Irealed one (IV).

The histological study revealed that ovariectomy resulted in reduction in the thickness of the compact as well as the trabecular bones. Both showed many osteoporotic cavities and osteoclasts eroding their surfaces. Large cartilaginous areas occupying the bone trabeculae, loss of trabecular connection resulting in increased trabecular free ends with disturbed trabecular architecture and widening of the bone marrow cavities showing fat cells were also demonstrated. Treatment with camosine resulted in disappearance of the osteoclastic resorption activity and increase the number of osteocytes in the compact and trabecular bones as well as proliferation of the cartilaginous plate with the appearance of osteocytes within the cartilaginous areas occupying the bone trabeculae denoting active process of bone formation. However, early treatment with camosine (group III) was more effective than the late treatment (Group IV) in preservation of compact bone shell thickness, intertrabecular connectivity and trabecular architecture with reduction of the trabecular free ends.

From the present work, it is concluded that bilateral ovariectomy results in marked increase of bone loss with destruction of bone architccture and that carnosine has both a stimulatory effect on bone formation as well as an inhibitory effect on bone resorption. Early carnosine intervention is recommended for better preservation of the normal bone structural clements.

\section{REFERENCES}

1. Abe, H. (1991) : Inter-organ transport and catabolism of camosine and anserine in rainbow trout. Comp. Biochem. Physiol., B 100 : 717 - 720.

2. Bogardus, S.; Boissonneault, G. and Decker, E. (1992) : In vitro LDL oxidation is decreased by carnosine. FASEB J. $6: 4$. 
3. Boldyrev, A. and Severin, S. (1990) : The histidine-containing dipeptides carnosine and anserine : distribution, properties and biological significance. Adv. Enzyme Regul., 30 : 175 - 194.

4. Castelo-Branco, C. (1998) : Management of osteoporosis. Drugs Aging., 12 (1) : $25-32$.

5. Chen, L.; Zeng, T.; Xia, W.; Li, H. and Zhou, M. (2000) : The eflect of estrogen on the restoration of bone mass and bone quality in ovariectomized rats. $J$. Tongji Med. Unv., 20 (4) : 283 - 286.

6. Chow, J., Lean, J. and Chambers, O. (1992) : 17 B-estradiol stimulates cancellous bone formation in female rats. Endocrinol, $130: 3025-3032$.

7. Colditz, G. (1998) : Relationship between estrogen levels, use of hormone replacement therapy and breast cancer. J. Natl. Cancer Inst., 90 (11) : 814 - 823.

8. Ermakova, V.; Babizhav, M. and Bunin, A. (1988) : Biological significance of histidine-containing dipcptides. Bull. Exp. Biol. Med., $101: 451$ - 453 .

9. Gibaldi, M. (1997) : Prevention and treatment of osteoporosis. J. Clin. Pharmacol., $37(12)$ : 1087 - 1099.

10. Hashizume, M. and Yamaguchi, M. (1994) : Effect of beta-alanyl-Lhistidinato zinc on differentiation of osteoblastic MC3T3-E1 cells : increases in alkaline phosphatase activity and protein concentration. Mol. Cell Biochem., 131 (1): 19 - 24 .

11. Jerome, C.; Burr, D.; Van Bibber, T.; Hock, J. and Brommage, R. (2001) : Treatment with human parathyroid hormone (1 - 34) for 18 months increases cancellous bone volume and improves trabecular architecture in ovaricctomized cynomolgus monkeys. Bone, 28 (2) : 150 - 159.

12. Kinney, J.; Ryaby, J.; Haupt, D. and Lane, N. (1998) : Three dimentional in vivo morphometry of trabecular bone in the ovariectomized rat model of osteoporosis. Technol. Health Cares, 6 (5 - 6) : 339 - 350.

13. Kishi, S.; Segawa, Y. and Yamaguchi, M. (1994) : Histomorphological confirmation of the preventive effect of beta-alanyl-L-histidinato zinc on bone loss in ovariectomized rats. Biol. Pharm. Bull., 17 (6) : 862 - 865.

14. Kishi, S. and Yamaguchi, M. (1994 - a) : Inhibitory effect of zinc compounds on osteoclasts-like cell formation in mouse marrow cultures. Biochem. Pharmacol., $48(6)$ : 1225 - 12230.

15. Kishi, S. and Yamaguchi, M. (1994 - b) : Stimulatory effect of beta-alanyl-Lhistidinato \%inc on alkaline phosphatase activity in bone tissues from elderly rats : comparison with zinc sulfate action. Biol. Pharm. Bull., 17 (2) : 345 - 347. 
16. Lane, N.; Haupt, D.; Kimmel, D.; Modin, G. and Kinney, J. (1999) : Early estrogen replacement therapy reverses the rapid loss of trabecular bone volume and prevents further deterioration of connectivity in the rat. J. Bone Miner. Res., $14(2): 206-214$.

17. Liao, E.; Luo, X. and Su, X. (2002) : Comparison of the effects of 17 beta-E2 and progestcrone on the expression of osteoprotegerin in normal human osteoblast-like cells. J. Endocrinol. Invest., 25 (9) : 785 - 790.

18. Lindsay, R.; Hart, D.; Forest, C. and Baired, C. (1980); Prevention of spinal osteoporosis in ovariectomized women. Lancet, 2 : 1152

19. MacFarlane, N.; McMurray, J.; O'Dowd, J.; Dargie, H. and Miller, D. (1991) : Synergism of histidinyl dipeptides as antioxidants. J. Mol. Cell. Cardiol., $23: 1205-1207$.

20. Masson, P. (1924) : Some histological methods, trichrome staining and their preliminary technique. Bull. Int. Ass. Med., $12: 72$.

21. Parfitt, A.; Mathews, C.; Villanueva, A.. Kleerekopek, A.; Frame, B. and Rao, D. (1983) : Relationships between surface, volume and thickness of iliac trabecular bone in aging and in osteoporosis. J. Clin. Invet., $72: 1396$ - 1409.

22. Perelman, M.; Kornilova, Z.; Paukova, V.; Biokov, A. and Primak, A. (1989) : Effect of carnosine on healing lung wounds. Bull. Exptl. Biol. Med., $108: 1329$ - 1333.

23. Riggs, B. (2002) : Endocrine causes of age-related bone loss and osteoporosis. Novartis Found. Symp., $242: 247$ - 259.

24. Riggs, B.; Khosla, S. and Melton, L. (1998) : Estrogen deficiency causes both type I and type II ostcoporosis in postmenopausal women and contributes to bone loss in aging men. J. Bone Miner. Res., 13 (5) : 763 - 773.

25. Segawa, Y.; Tsuzuike, N.; Tagashira, E. and Yamaguchi, M. (1992) : Preventive effect of beta-alanyl-L-histidinato zinc on bone metabolism in rats fed on low - calcium and vitamin D - deficient diets. Res. Exp. Med. (Berl), 192 (3) : 213 219.

26. Segawa, Y.; Tsuzuike, N.; Tagashira, E. and Yamaguchi, M. (1993) : Preventive effect of beta-alanyl-L-histidinato zinc on the deterioration of bone metabolism in ovariectomized rats. Biol. Pharm. Bull., 16 (5) : 486 = 489.

27. Seifert-Klauss, V.; Mueller, J.; Lur „a, P.; Probst, R.; Wilker, J.; Hoss, C.; Treumannn, T.; Kastner, C. and Ulm, K. (2002) : Bone metabolism during the perimenopausal transition : a prospective study. Maturitas, 41 (1) : 23 - 33. Pr 
28. Soliman, K. and Abdel Monem, E. (2001) : Acute Toxicity study and screening of some pharmacological effects of carnosine on certain smooth muscke; Kasr El-Aini Med. J., 7 ; 225 - 252.

29. Soliman, K. and Ali, H. (2003) : Promoting effect of carnosine on proteins in normal and partially hepatectomized mice. Egypt. J. Physiol., 5 (In Press).

30. Sugiyama, T.; Tanaka, H, and Kawai, S. (2000) : Improvement of periarticular osteoporosis in postmenopausal women with rheumatoid arthritis by betaalanyl-L-histidinato zinc : a pilot study. Bone Miner. Metab., 18 (6) : 335 - 338.

31. Sun, B.; Mitnick, M.; Eielson, C.; Yao, G.; Paliwal, I. and Insogna, K. (1997) : Parathyroid hormone increases circulating levels of fibronectin in vivo : modulating effect of ovariectomy. Endocrinology, $138(9): 3918$ - 3924.

32. Turner, R.; Walkely, G.; Hannon, K. and Bell, N. (1987) : Tamoxifen prevents the skeletal effects of ovarian hormone deficiency in rats. J. Bone Miner. Res. 2 : 449 - 456.

33. Vaananen, H. and Harkonen, P. (1996) : Estrogen and bone metabolism. Maturitas, 23 Suppl : S $65-69$.

34. Watts, N. (1999) : Postmenopausal osteoporosis. Obstet. Gynecol. Surv., 54 (8) : 532 - 538.

35. World Health Organization (1994) : Assessment of fracture risk and its application to screening for postmenopausal osteoporosis. Report of a World Health Organization study group Geneva : WHO : 1 - 25 ,

36. Wronski, T.; Cintron, M.; Doherty, A. and Dann, L. (1988) : Estrogen treatment prevents osteopenia and depress bone turnover in ovariectomized rats. Endocrinol. $123(2): 681$ - 686 .

37. Yamaguchi, M. (1995) : Beta-alanyl-L-histidinato zinc and bone resorption. Gen Pharmacol., 26 (6) : 1179 - 1183.

38. Yamaguchi, M. and Ehara, Y. (1996) : Effect of essential trace metal one bone metabolism in the femoral-metaphyseal tissues of rats with skeletal unloading : comparison with zinc-chelating dipeptide. Calcif. Tissue Int., 59 (1) : 27 - 32.

39. Yamaguchi, M. and Hashizume, M. (1994 - a) : Effect of parathyroid hormone and interleukin-1 alpha in osteoblastic MC3T3-E1 cells : interaction with betaalanyl-L-histidinato zinc. Peptides, 15 (4) : 633 - 636.

40. Yamaguchi, M. and Hashizume, M. (1994 - b) : Effect of beta-alanyl-Lhistidinato zinc on protein components in osteoblastic MC3T3-E1 cells : increase in osteocalcin, insulin-like growth factor-I and transforming growth factor-beta. Mol. Cell Biochem., 136 (2) : I63 - 169. 
41. Yamaguchi, M. and Kishi, S. (1993) : Prolonged administration of beta-alanylL-histidinato zinc prevents bone loss in ovariectomized rats. Jpn. J. Pharmacol., 63 (2) : $203-207$.

42. Yamaguchi, M. and Kishi, S. (1994 - a) : Comparison of the effect of betaalanyl-L-histidinato zinc and its zinc-chelating ligand on bone metabolism in tissue culture. Biol. Pharm. Bull., 17 (4) : 522 - 526.

43. Yamaguchi, M. and Kishi, S. (1994 - b) : Effect of zinc-chelating dipeptide on bone metabolism in weanling rats : comparison with beta-alanyl-L-histidinato zinc-related compounds. Peptides, 15 (4) : 671 - 673.

44. Yamaguchi, M. and Kishi, S. (1995 - a) : Inhibitory effect of zinc-chelating dipeptide on parathyroid hormone-stimulated ostcoclasts-like cell formation in mouse marrow cultures : involvement of calcium signaling. Peptides, 16 (4) : 629 $-633$.

45. Yamaguchi, M. and Kishi, S. (1995 - b) : Differential effect of transforming growth factor-beta on ostcoclast-like cell formation in mouse marrow culture : relation to the effect of zinc-chelating dipeptides. Peptides, $16(8): 1483-1488$.

46. Yamaguchi, $M$. and Kishi, S (1996) : Zinc compounds inhibit ostcoclast-like cell formation at the earlier stage of rat marrow culture but not osteoclast function. Mol. Cell Biochem., 158 (2) : 171 - 177.

47. Yamaguchi, M.; Kishi, S. and Hashizume, M. (1994) : Eflect of zinc-chelating dipeptides on osteoblastic MC3T3-El cells : activation of aminoacyl-tRNA synthetase. Peptides, 15 (8) : 1367 - 1371.

48. Yamaguchi, M. and Matsui, T. (1996) : Stimulatory effect of Zinc-chelating dipeptide on deoxyribonucleic acid synthesis in osteoblastic MC3T3-El cells. Peptides, 17 (7) : 1207 - 1211.

49. Yamaguchi, M. and Matsui, T. (1997) : Zinc chhancement of 17 beta-estradiol in osteoblastic MC3T3-E1 cells. Calcif. Tissue Int.. 60 (6) : 527 - 532. 


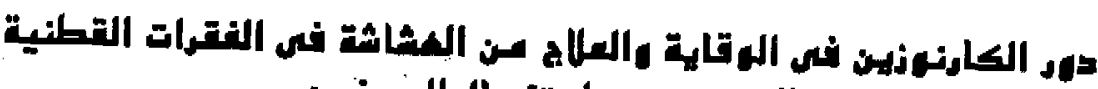

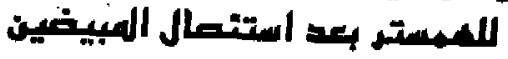

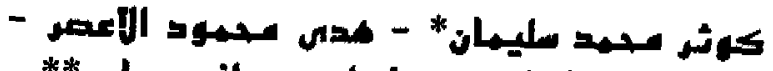

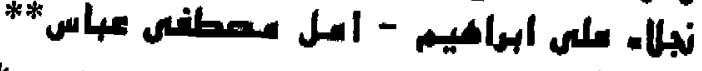

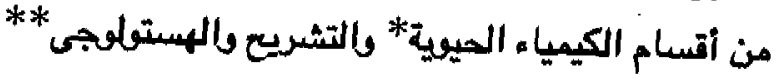

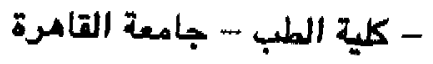

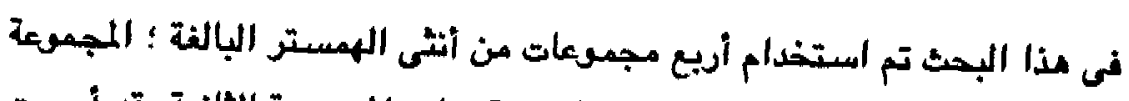

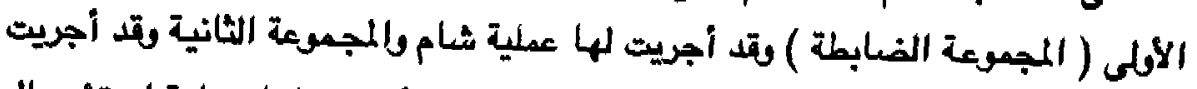

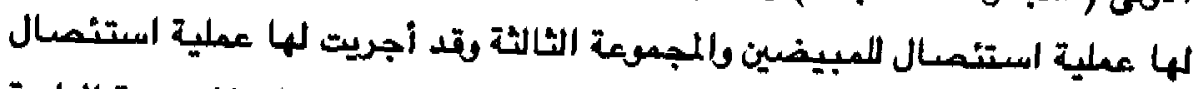

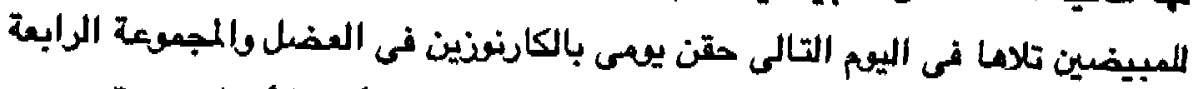

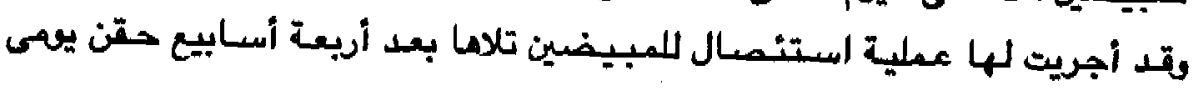

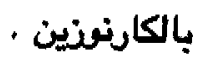

ققد تمت التضحية بحيوانات المجموعات الأولى قالثانية والثالثة بعد أريعة وستة

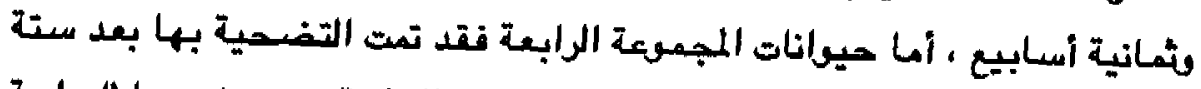

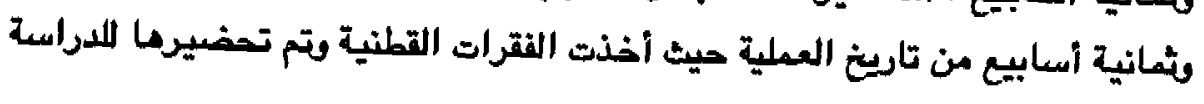

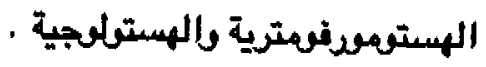

قتد أظهرث القياسات المودفومترية انخفاضـا متفيرا وذو دلالة إحصائية فى قيم

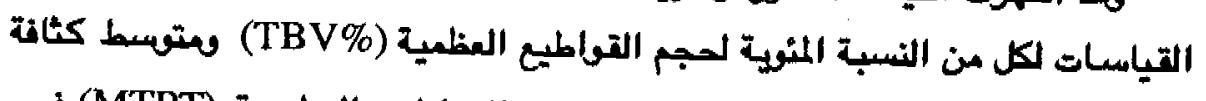

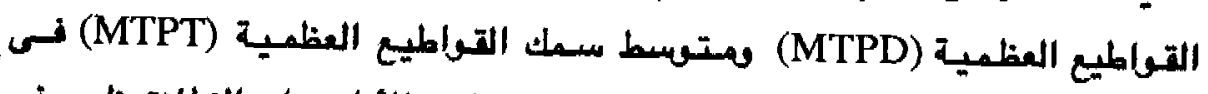

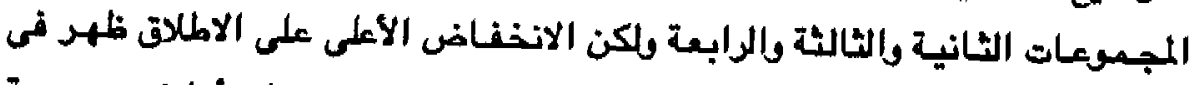

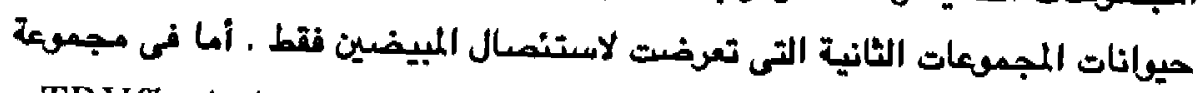

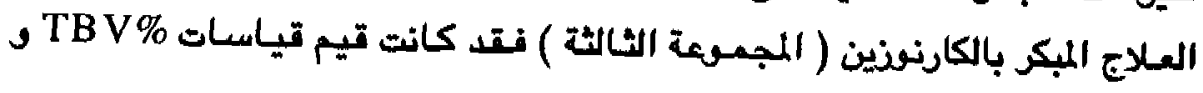




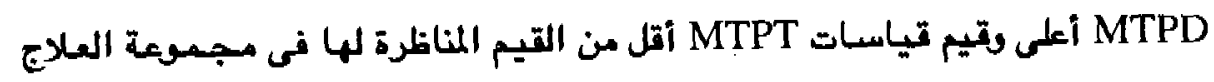
المتأخر بالكارنوزين ( المجموعة الرابعة ) .

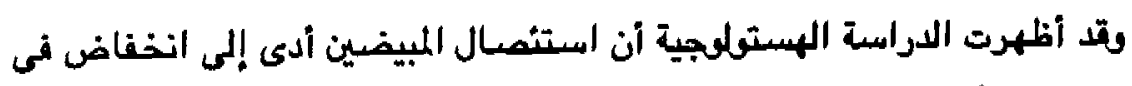

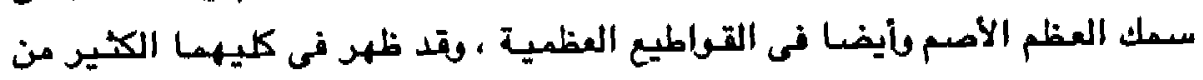

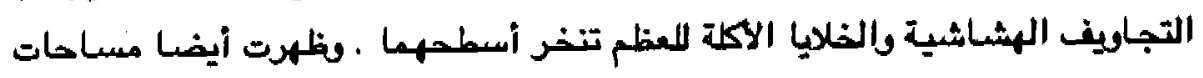

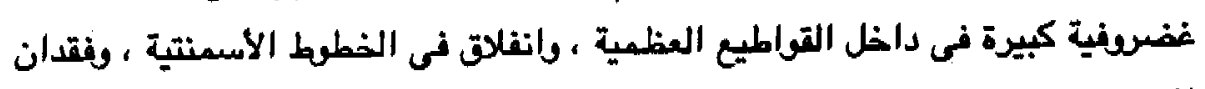

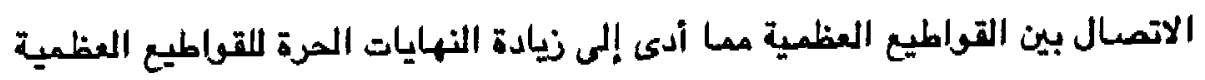

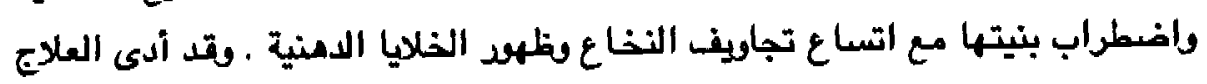

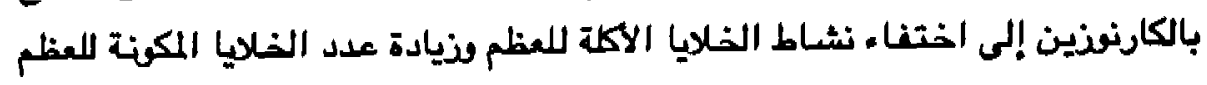

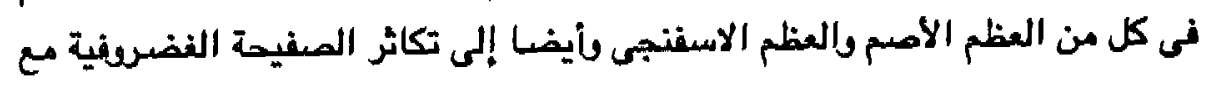

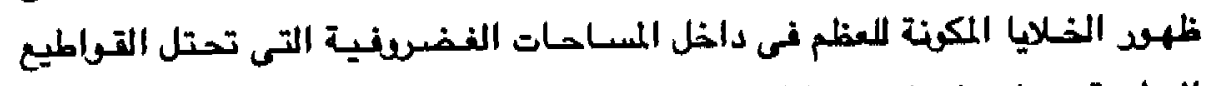

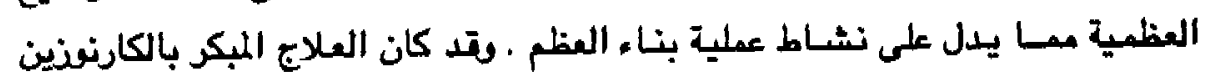

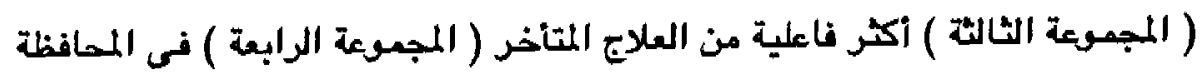

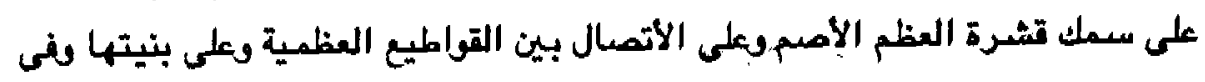

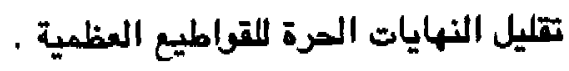

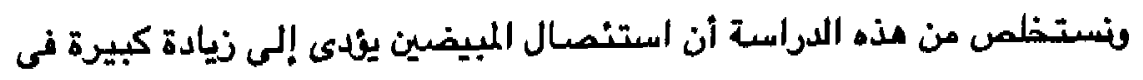

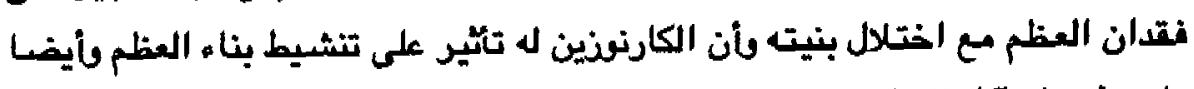

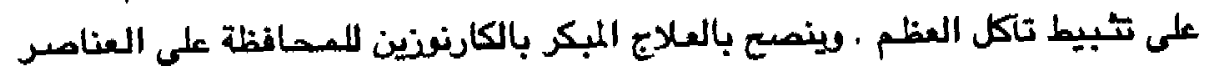
الطبيعية الإنشانية للعظم .

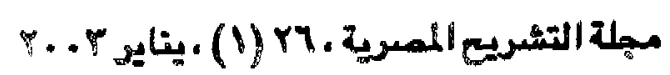

